Reevaluating the role of innovation in education: a living social process
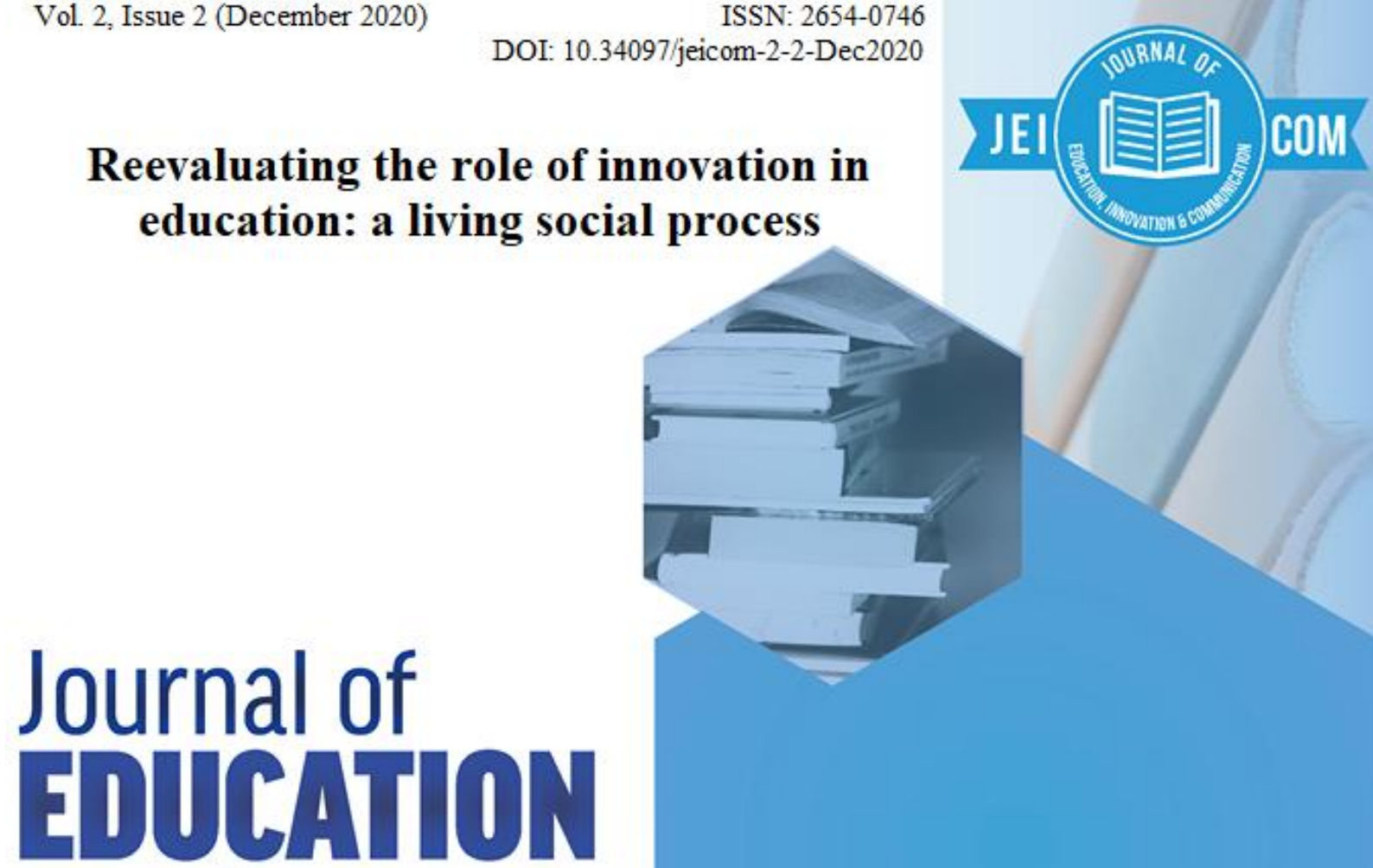

INNOVATION and COMMUNICATION

Editors in Chief

Margarita Kefalaki

Fotini Diamantidaki

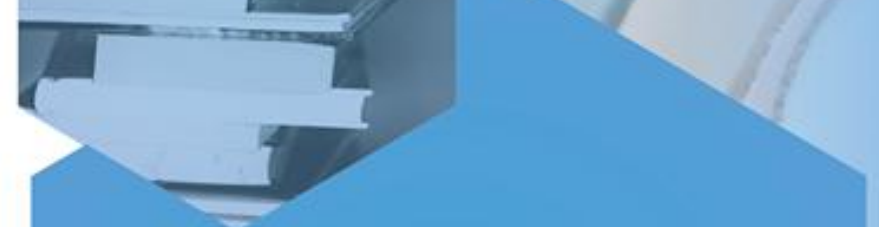


Journal of Education, Innovation and Communication

\section{Reevaluating the role of innovation in education: a living social process}

Vol. 2, Issue 2 (December 2020)

ISSN: 2654-0746 (listed in the National Library of Greece)

DOI: 10.34097/jeicom-2-2-Dec2020

https://doi.org/10.34097/jeicom-2-2-Dec2020 


\section{Editor's message}

The "Journal of Education, Innovation, and Communication (JEICOM)" is a fully double Peer-Reviewed Open Access and free of any charge journal, publishing articles from all areas of education, innovation and communication. JEICOM's scope is to provide a free and open platform to academics, researchers, professionals, and postgraduate students to communicate and share knowledge in the form of high quality empirical and theoretical research that is of high interest not only for academic readers but also for practitioners and professionals.

JEICOM welcomes theoretical, conceptual and empirical original research papers, case studies, book reviews that demonstrate the innovative and dynamic spirit for the education and communication sciences, from researchers, scholars, educators, policy-makers, and practitioners in education, communication, and related fields. Articles that show scholarly depth, breadth or richness of different aspects of social pedagogy are particularly welcome.

The research papers presented every year during the conferences organized by our Institute, the Communication Institute of Greece, enables us and our editorial board, to have access to a plethora of papers submitted. Following a rigorous double peer-reviewed process only a selection of the papers submitted, is published twice a year.

We are glad to announce that our annual events for 2021 are proposed both remotely and face-to-face, so that educators, researchers, professionals and individuals are able to join, even with possible travel restrictions. For 2021 we propose three opportunities to meet: The $6^{\text {th }}$ Annual International Conference on Communication and Management (ICCM2021), 1-5 August 2021, he $2^{\text {nd }}$ International Hellenic Conference on Political Sciences. Communicating in Politics? (HEPO2021), 1-5 August 2021, and the $2^{\text {nd }}$ International Conference on Education (EDU2021), 8-12 August 2021.

The current issue of the "Journal of Education, Innovation, and Communication (JEICOM)", is the second issue of the second volume (December 2020).

Dr Margarita K. Kefalaki \& Dr Fotini Diamantidaki 


\section{Editors in Chief}

*Dr Margarita K. Kefalaki, President, Communication Institute of Greece \& Adjunct Professor, Hellenic Open University, Greece

*Dr Fotini Diamantidaki, Lecturer in Education, UCL Institute of Education, University of London, UK

\section{Editorial Team}

*Dr Robert J. Bonk, Professor of Professional Writing, School of Human Service Professions, Widener University, Chester, USA

*Dr Jurgen Rudolph, Head of Research \& Academic Partner Liaison, Kaplan Higher Education, Singapore \& Editor, JALT Journal, Singapore

*Dr Michael Nevradakis, Communications Instructor, Deree-American College of Greece, Department of Communications, Greece

*Dr Shirley Lawes, Department of Culture Communication and Media, UCL Institute of Education, UK

*Dr Karl-Heinz Pogner, Associate professor, Department of Management, Society, and Communication, Copenhagen Business School, Denmark

*Dr Nathan Herbst, Ph.D., Team Coordinator, Great Commission Alliance, USA

*Dr Hazel Crichton, Lecturer in Modern Languages, The School of Education, The University of Glasgow, Glasgow

*Dr Carolin Rekar Munro, Professor, School of Business, Faculty of Management, Royal Roads University, Victoria, British Columbia, Canada

*Dr Michael A. Altamirano, Professor, King Graduate School, Monroe College, Bronx, New York, USA

*Dr Michael Sutton, Game-Based Learning Author, Educator, Innovator, \& Facilitator, Researcher, Edupreneur, USA

*Mrs Lydia Lymperis, Doctoral Researcher in Education, UK

*Dr Carlos E. Rios-Collazo, Professor, Monroe College, New York, NY, USA

* Dr Hasan Saliu, Dean of Faculty of Mass Communication, AAB College, Pristina (Kosovo)

*Sophie Karanicolas, Hon. Associate Professor, Adelaide Dental School, Adelaide Health and Medical Sciences, The University of Adelaide, Australia

*Dr Paraskevi Kontoleon, Lecturer, University of South Australia, Australia

*Dr Eirini Daskalaki, Academic Director \& Head of Research Centre at ACC Akademia College, Research Fellow at Cyprus Institute of Marketing (CIM), Cyprus 
*Dr Nikleia Eteokleous, Assistant Professor in Educational Technology, School of Education and Social Sciences \& Head of the Distance Learning Committee Coordinator of M.Ed. in Curriculum Development and Instruction, Co-founder Robotics Academy, Cyprus

*Dr Christopher (Chris) Harris, Chief Operating Officer, At-Sunrice GlobalChef Academy, Singapore

*Dr Matt Glowatz, Assistant Professor, University College Dublin, Ireland

*Dr Anne Palmer, PGDip Education \& BA(Hons) (UWA) Murdoch Singapore Pte Ltd, Singapore

* Dr Bashar Malkawi, Dean and Professor of Law, University of Sharjah, Sharjah-UAE

*Dr Max Caruso, Western Co-Principal, Yew Wah International Education School of Zhejiang Tongxiang, China

*Dr Yuan Ying Caruso, Ambassador COMinG \& Chinese Co-Principal YWIES Shanghai, China

*Dr Jane Jones, Senior Lecturer, Subject Director MFL Teacher Education, Department of Education and Professional Studies, University of Kings College London, UK

*Dr Frances Weightman, Associate Professor, University of Leeds, UK

*Dr Jennifer Eddy, Associate Professor and program director, World Language Education, Queens College, City University, USA

*Dr Dean Cleavenger, Lecturer, School of Business Administration, Department of Management, University of Central Florida, USA

*Dr Francine Hultgren, Professor and Chair, University of Maryland, Department of Teaching and Learning, Policy and Leadership, United States, USA

*Dr Bill Baker, Lecturer, University of Tasmania, College of Arts, Law and Education, School of Education, Australia

*Dr Emmanouil Takas, Instructor, Cardiff Metropolitan University, City Unity College, Greece

*Dr John F. Covaleskie, Professor Emeritus, ELPS, Women and Gender Studies, Center for Social Justice, University of Oklahoma, USA

*Dr Lia-Paschalia Spyridou, Assistant Professor, Faculty of Communication and Media, Cyprus University of Technology, Cyprus 


\section{Contents}

-Reevaluating the role of innovation in education: a living social process. Preface

Dr Fotini Diamantidaki \& Dr Margarita K. Kefalaki

-Why do digital teaching innovations so often fail?

Professor Justin O’Brien

-Reverse Bloom: A new hybrid approach to experiential learning for a new world Dr Arthur W Shelley

- Equipping Parents for Effective HOME Schooling

John Kinzer \& Dr Nathaniel Herbst \& Philip Pohlman \& Erin Herbst

-Evaluating Mandarin language students' online experience during Covid-19: A case study from London

Li Qing \& Dr Fotini Diamantidaki

-Book review "Why is it worth waking up every morning? Impressions and reflections on inspiration, motivation, and collaboration"

Dr Sotirios Maipas 


\section{Reevaluating the role of innovation in education: a living social process Preface}

Journal of Education, Innovation and Communication (JEICOM)

Vol. 2. Issue 2, December 2020 DOI: 10.34097/jeicom-2-2-Dec2020-0

\section{Dr Fotini Diamantidaki ${ }^{1}$ \\ $\&$ \\ Dr Margarita Kefalaki ${ }^{2}$}

Education is a social process, 'a process of living and not a preparation for future living' (Dewey: 1916). It requires educators to interact with other people in real time with the hope to bring out their full potential. It is grounded in collaboration, mutual respect and inclusive practices. If education is a process of living and not a preparation for it, it should then reflect what happens in life and it should emerge and evolve from any circumstances. Including the most unprecedented ones.

Innovation equally emerges from unpredictable circumstances - 'Necessity is the mother of invention' (Plato in Ferrari: 2000). Educational innovations aim to improve teaching and learning, social innovations aim to improve the way we live. Lately, innovation is particularly associated alongside advances in technology; however, technological innovations need a strong theoretical foundation, a systematic purposeful approach and a grounded theory in pedagogy (Serdyukov, 2017). However, at the core of any advancement is us humans: 'the real mechanism to influence our future is a distinct sphere of human culture' (Mykhailyshyn et al., 2018: 10).

Our issue aims to add to the existing knowledge on innovation that have influenced teaching and learning processes during the pandemic with the hope that this issue will help us reevaluate the purpose of innovations and their impact on our everyday life.

\footnotetext{
${ }^{1}$ Lecturer in Languages Education, UCL centre of Applied Linguistics, UK. Email: f.diamantidaki@ucl.ac.uk

${ }^{2}$ Adjunct Professor, Hellenic Open University \& President, COMinG, Greece. Email: mke@coming.gr
} 
Professor Justin Peter O'Brien, signs the first paper of this issue, entitled 'Why do digital teaching innovations so often fail?' This research paper makes a case to dispel the unhelpful narrative of technophobic instructors struggling to teach homogeneous tech savvy digital natives, but to recognise a nuanced continuum of digital capabilities, for both students and instructors. The author suggests that educators should seek to collaborate with students to choose how they interact using digital tools, recognising the importance and diversity of public-private boundaries and consider the need for this to take place beyond the gaze of faculty.

The second paper by Dr Arthur W. Shelley, entitled 'Reverse Bloom: A new hybrid approach to experiential learning', brings forward three key new contributions to the literature; The "Reverse Bloom Learning Framework" (RBLF), a set of principles to guide learning facilitation through the RBLF and insights on designing inclusive learning activities (including provision of deeper feedback for better reflection and higher quality learning outcomes). The article argues that these three elements together of progressive learning can enable a more balanced approach to learning at all levels. The RBLF includes all three of Bloom's domains in iterative social learning experiences and reverses the traditional order of Bloom's learning elements. The author suggests that the inclusive and comprehensive approach enables facilitation of more collaborative learning and this generates more competent, confident and capable graduates, who are better equipped to interact in our modern challenging workplaces and our wider world.

John Kinzer, Dr Nathaniel Herbst, Philip Pohlman and Erin Herbst, sign the third paper entitled 'Equipping Parents for Effective HOME Schooling'. The study presents a brief review of a cross-section of the literature on homeschooling issues as well as a succinct case study of a hybrid homeschool service. Based on that analysis, the authors present four ways to help equip parents for effective homeschooling and summarized into the HOME acronym. The acronym stands for $(\mathrm{H})$ helping families find their fit, $(\mathrm{O})$ offering a diversity of teaching resources, (M) making homeschooling socially acceptable, and (E) empowering homeschool partnerships.

Qing Li and Dr Fotini Diamantidaki sign the last article of this issue with an empirical paper entitled 'Evaluating Mandarin language students' online experience during Covid-19: A case study from London' examining teacher-student interactions that take place via online means and the students' sense of 'presence' (i.e., cognitive, social, and teaching presence) in order to evaluate the lessons we can learn from the online learning experience, going forward in terms of teaching and learning. This study also presents how meaningful and worthwhile 
the experience has been and how the sense of 'presence' plays a significant role in the process of online teaching and learning.

Finally, in this issue we present a book review by Dr. Sotirios G. Maipas for a book entitled 'Why is it worth waking up every morning?' The book itself aims to provide encouragement with impressions and reflections on inspiration, motivation, and collaboration and is created as a sign of hope, especially during the difficult times we face as a global collective (ex. COVID-19 global crisis, 2020). The publication is a production of well-known educators from all over the world and means to give a good example of collaboration, an example of humanity, dignity, hope and sensibility. The President and the Honorary Vice Presidents of the Communication Institute of Greece, creators of this book are, Dr Margarita Kefalaki, Sophia Karanicolas, Dr Michael A. Altamirano, Dr Ailson J. De Moraes, Dr Fotini Diamantidaki, Dr Robert J. Bonk, Dr Carolin Rekar Munro, Dr Jürgen Rudolph, Dr Christian Schnee, and Dr Karl-Heinz Pogner.

\section{References}

Dewey, J. (1916). Democracy and education: An introduction to the philosophy of education. New York: MacMillan.

Ferrari, G.R.F (2000) (Ed). Plato 'The Republic' (Cambridge Texts in the History of Political Thought), Cambridge University Press.

Mykhailyshyn H. Innovation of Education and Educational Innovations in Conditions of Modern Higher Education Institution / H. Mykhailyshyn, O. Kondur, L. Serman // Journal of Vasyl Stefanyk Precarpathian National University. - 2018. - Vol. 5. - № 1. P. 9-16, doi: 10.15330/jpnu.5.1.9-16, http://lib.pu.if.ua:8080/bitstream/123456789/1431/1/2793-8202-1-PB.pdf

Serdyukov P. (2017) Innovation in education: What works, what doesn't, and what to do about it? Journal of Research in Innovative Teaching \& Learning, 10 (1) (2017), pp. 433. 


\title{
Why do digital teaching innovations so often fail?
}

Journal of Education, Innovation and Communication (JEICOM)

Vol. 2. Issue 2, December 2020 DOI: 10.34097/jeicom-2-2-Dec2020-1

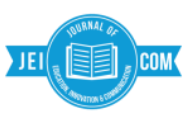

Professor Justin O’Brien ${ }^{3}$

\begin{abstract}
In a dynamic field, university marketing educators ought to harness new digital tools and social media platforms successfully in the curriculum, but evidence of its widespread adoption is meagre (Tuten \& Marks, 2012). By explicitly investigating exemplars of pedagogic innovation failure, this research paper analyses faculty and digital marketing student perspectives on the use of digital tools and social media for formal learning. This research paper makes a case to dispel the unhelpful narrative of technophobic instructors struggling to teach homogeneous tech savvy digital natives, but to recognise a nuanced continuum of digital capabilities, for both students and instructors. Educators should seek to collaborate with students to choose how they interact using digital tools, recognising the importance and diversity of public-private boundaries and consider the need for this to take place beyond the gaze of faculty.
\end{abstract}

Keywords: Digital innovation failure; digital learning; education technology; faculty resistance; student experience.

\footnotetext{
${ }^{3}$ Professor, Executive Director of Postgraduate Programmes, Surrey Business School, University of Surrey, UK, email: University of Surrey. Email: just.obrien@surrey.ac.uk
} 


\section{Introduction}

Traditional lecture style teaching "simply does not work any more" (Lohman, 2016, p. 163), students are no longer content to be passive consumers posits Selwyn (2012), they should be seen rather as active co-producers of a new pedagogy. Lee and McLoughlin (2010) eulogise about an emergent culture of technologically enabled learning that liberates collective exploration, play and innovation over individualised instruction. Perhaps, as Thayne and Cooper (2014) believe, social media is the much-needed trust change catalyst and staffstudent bond enhancer in the digital space which Dabbagh and Kitsantas (2012) argue should be used to create informal and formal learning spaces. However, Espuny, Gonzalez Martinez, Fortuno and Gisbert Cervera (2011) lament that the enormous potential of new digital tools, including social networks, is inhibited by the legacy of the one-way information flow pedagogy, the outmoded lecture and seminar format that was still favoured by many universities prior to the Coronavirus pandemic.

However, an emergent approach sees web-enabled technologies applied in an increasingly personal, social and participatory manner; posit McLoughlin and Lee (2010). Social media tools (e.g. Microsoft Teams) have the potential to enable rich learning such as: effective resource sharing, collaborations, peer-to-peer interaction and augmented communication skills, a space where traditional learning management systems have had limited traction according to Espuny et al (2011). Sharples et al (2016) note social media's potential to develop conversations and to foster learning through the sharing of ideas but also identify the challenge novice learners face in discerning inaccurate and biased sources and the requirement to have sufficient personal resilience to handle hostile responses.

With breakthrough technologies surfacing annually (Shaltoni, 2016), Prensky (2001, p. 2) highlighted that "students are no longer the people our educational system was designed to teach" citing a significant discontinuity. Johnson and Jones (2010) signal that the fast-paced change in technology makes it difficult for educators to retain their subject currency and suggest that there are important generational gaps between instructors and digital native students, whilst Duffy and Ney (2015) believe that the application of digital technology tools have been ad hoc and not sufficiently systematic.

Some lament the just-in-time shift from what we know 'cultivators' to what we can find out for ourselves, described by Carr (2010) as 'digital hunters and gatherers'. In considering this momentous digital challenge, Crittenden \& Crittenden (2015) highlight the need for universities to ensure that marketing students have the prerequisite skills needed to compete for marketing jobs with graduates of more numerate subjects.

Selwyn (2012, p. 214) uses the uncomplimentary term mongrel to describe the education and technology (edtech) non-field, one that attracts a "transient ragbag of individuals" from across the disciplines. Roberts and Micken (2015) posit that significant literature gaps exist in how to present digital concepts and point at a dearth of pedagogic strategies on how to teach digital marketing effectively. It is hard to find examples of failure in the management pedagogy literature, this despite the popularity of the entrepreneurial fail fast mantra (Hirsch, 2012), Haig's (2005) Brand Failures text is a rare scholarly example of codified dissemination of marketing learning from calamity. It is perhaps difficult to present the scholarly contribution of an innovation failure, because of the potential reputational 
implications for both the scholar(s) and their institution(s). It is therefore not unsurprising that research in this field is typically penned by optimistic, pioneering tech evangelists keen to promulgate their successes, promoting new innovations, that are written up in a way to suggest that they are for the most part uncomplicated and effective (for example, see: Evans 2014; Moran et al., 2011).

So, recognising a field that is perhaps overly represented by rosy accounts of innovative digital pedagogic success, this research study turns its head and seeks to understand why nonmandatory digital learning augmentation often fails, by analysing anonymous interviews with marketing management faculty innovators and undergraduate students of digital marketing. This paper uses eleven semi-structured faculty interviews to solicit experienced, UK-based university marketing and management educators' reflective accounts on pedagogic social media innovations that have failed to live up to their expectations. It then juxtaposes these teacher perspectives with insights from ten digital marketing student interviews, aiming to explore the manifest tensions a proactive marketing educators attempt to transform their teaching practice. A number of important recommendations are identified, aimed at learning the lessons from relative failures using a less trodden investigational path. The literature review starts by critically considering the idea that social media is merely the latest pedagogic nirvana, before progressing to consider published insight on staff and then students' social media expectations, and concludes by summarising the challenges faced by faculty seeking to institute transformational digital technologies in their classrooms. Problems and challenges faced by educators are often given limited attention in pedagogic innovation papers. This research's contribution is to provide a contemporary account of marketing educators' failures when attempting to use digital tools in university teaching.

\section{Social media hype: the latest digital pedagogic nirvana}

University students now have very different expectations of their teaching and learning experience, changes driven by their evolving relationships with technology (Brown \& Watson, 2017). Mobile and socially connected technology affords opportunities for interaction, communication, collaboration and content creation like never before (Grant, 2013). McLoughlin and Lee (2010) believe that university education should be moving from knowledge-focused content delivery to designing transformational experiences that enable personal learning that simultaneously encompasses skills and capabilities development.

In some areas, notably in the marketing discipline, there has been growing focus on new digital and social media based tools to mediate and enhance teaching with the aim of fostering active learning in students, and Tess (2013) surmises that whilst some scholars make the case for university educators to integrate more digital assets into their curricula, the largely self-reported evidence set for this is lagging. Gikas and Grant (2013) have highlighted that ubiquitous ownership of internet connected, powerful mobile devices (creating a serendipitous Bring-Your-Own- Device networked platform) has afforded educators the opportunity to enhance student communication, interaction and collaboration. This digital and social media enabled, many-to-many, participatory collective offers the potential to foster enhanced collaboration, conviviality and creativity (Gikas \& Grant, 2013; Selwyn, 2012). However, Solomon (2016, p. 150) warns of the over-promise of technology; "rash, misplaced and misconceived" investments in silver bullet gadgets. As highlighted by Gouseti (2010), 
are we again, merely in the midst of the latest iteration of a familiar technological cycle of hype, hope and disappointment?

\section{Staff attitudes towards social media and collaborative digital tools}

Lohman (2016) believes professors are now expected, as an absolute minimum, to include learning tools far beyond PowerPoint slides but also a full range of 'traditional' social media platforms, comprising: Twitter, Facebook, Skype and YouTube shorts, according to Shaltoni (2016). Brocato, White, Bartkus and Brocato (2015) argue that it is imperative to integrate digital into the curriculum to ensure marketing graduates possess a competitive skill set. Social media technology is defined by Davis et al $(2012$, p. 1) as "web-based and mobile applications that allow individuals and organisations to create, engage, and share new usergenerated or existing content, in digital environments through multi-way communication". Moreover, Blankenship (2011) suggests that interactive community tools such as: Skype, Twitter, Facebook, YouTube, Blogs and wikis, are becoming omni-prevalent in university classrooms, but it is not clear that this so-called engagement is actually much more than an occasional video clip in reality.

Faculty, according to Roblyer, McDaniel, Webb, Herman and Witty (2010) have been prone to prohibiting popular student technologies, citing in particular Facebook, and are more likely to prefer traditional platforms, namely email. Rather than embracing the opportunity for developmental change, it is not unusual for digital technophobes to require their students to turn off their mobile devices in class, banning social media and even dismantling wireless hubs (Thomas, 2011). Buzzard, Crittenden, Crittenden and McCarty (2011) noted a faculty preference for student engagement via the learning management system, whilst students preferred web-based tools and even email. Furthermore, Roblyer et al. (2010) claim that universities possess a well-established culture of non-adoption of new technologies, describing faculty as laggards. Tuten and Marks (2012) noted that marketing academics use social media in their personal lives, but posit that it is not used widely for educational purposes. Davis et al. (2012) identified that community college leaders thought that social media had minimal to moderate value pertaining to learning outcomes. They saw value through personal use in; community building on campus, facilitating staff-student interaction, cascading events information and as student feedback channel. Contradictory research evidence from the Babsom Survey Research Group (Moran et al., 2011) suggests that faculty are big believers in social media, with two thirds of their sample using social media in class (typically online video) and $30 \%$ posted content for beyond class engagement, with video, podcasts and wikis cited as the most valuable collaborative learning tools. It would appear from the above that there are disparate perspectives, and points, perhaps unsurprisingly, towards a more heterogenous picture of digital adoption.

\section{Students expectations in a post web 2.0 , social media age}

Students are increasingly self-organised, self-sufficient, flexible and fluid; habituated to and comfortable with multitasking, digital juggling and exercising more autonomy over their lives (Selwyn, 2012). Hargittai (2008) advised that it is not wise to assume that all students will share the same levels of interest, motivation and affinity for utilising social media. Many students were found to be uncomfortable communicating online, according to Munoz and 
Wood (2015), and convincing students that they do not already know everything about social media was a significant challenge. Intriguingly, they found a large number of students were resistant adopting new technology and/ or creating an online presence (Munoz \& Wood, 2015). Critically, Selwyn (2012) posits that student social media use is not always equitable, highlighting important divisions by race, gender, age and socio-economic differences. Buzzard, Crittenden, Crittenden, and McCarty (2011) noted the adoption of contemporary tools for entertainment and communication, but not necessarily for education purposes. Moreover, Selwyn (2012) highlights a lack of sophisticated use of social media by university students, despite its significant potential for communal activity, it is primarily used for oneway passive content consumption. Prevalent is a social media ethos where the majority lurk, free-riding the creative, often altruistic, efforts of a minority.

Taylor, Mulligan and Ishida's (2012) research findings support growing evidence that management students do not welcome the formal academic use of Facebook and underpinning this position Karl and Peluchette (2011) identified that suspicious faculty friend requests made many students feel uneasy. However, contradictorily, Dearbone (2014) noted that despite a student preference for little or no faculty self-disclosure, students did not find Facebook teacher friendships invasive, but that the majority would only accept an invitation because they felt compelled to, and they had mixed feelings about the pedagogic use of Facebook, although effective, because it stripped the site of its intended social role. Elliott (2011) also identified student feedback that valued an enduring, personal relationship with their university educator.

Kassens-Noor (2012) found that the always-available, micro- blogging tool Twitter fostered the creation of better group knowledge than traditional methods, notable for connecting students beyond the classroom environment, but its short text limit constrained self-reflection and critical thinking. Al-Bahrani and Patel (2015) insight indicates that students may prefer one-way sharing social media platforms such as Twitter and Instragram, rather than more intrusive, two- way friending in Facebook. Junco, Heibergert and Loken (2011) and Evans (2014) found that Twitter usage increased student engagement, Johnson (2011) evidenced that Twitter enhanced the credibility of the tutor, whilst Lowe and Laffey (2011) found, in a study with a $65 \%$ voluntary uptake, that interactions enhanced enjoyment, subject learning and employment skills. The instant messaging platform Whatsapp was found by Rambe and Bere (2013) to foster spontaneous discussions, independent learning, confidence building and collaborative resource generation, but there was resentment of the encroachment of academic life into the family sphere from mature students and ambivalence to wider usage.

The literature specifically considering Twitter, Whatsapp and Facebook seems to support Lee and McLoughlin's (2010) view that social media can enrich learning, but that not all students are comfortable in partnering in Selwyn's (2012) active, co-produced vision. Although a number of successful social media pedagogic innovations have been cited, underscoring its potential to enhance learning, student support for them does not appear to be unanimous. 


\section{Faculty challenges: digital teaching}

To be successful, university educators need to convincingly deliver novel, relevant communications by experimenting with emergent technologies (Johnson \& Jones, 2010), a position that is supported by Fose and Mehl (2007) who believe that fun and creativity enhance learning, particularly when seeking to compete for limited student attention bandwidth. McLoughlin and Lee (2010) posit that the pedagogic challenge presented by online collaboration is more than just demonstrating competence with particular tools, staff need to effectively and authentically integrate them into the new learning experience. Similarly, Munoz and Wood (2015) believe there is an important paradigm shift away from social media as entertainment towards being recognised as means facilitate collaboration and to develop valuable skills. Although they do warn of the rapidly changing landscape that can require a different course every semester and the heavy workload challenge of remaining current. Johnson and Jones (2010) also recommend that educators undertake more experiential research to develop their digital knowledge to ensure students are provided with vocationally valuable learning experiences. However, part of the appeal of social media is its lack of control, so lecturers need to realise this potential without undermining the inherent value students attribute to them by not controlling learning, through the one-way broadcasting information, but to facilitate successful student-student and student- staff interactions (Siemens \& Weller, 2011).

Hybrid digital spaces can lead to a blurring of private- public boundaries, which raise important privacy issues (Lewis et al., 2008), appropriating student's peer networkingenvironments can be perceived as an invasion of their space (McLoughlin \& Lee, 2010). Moran, Seaman and Tinti- Kane (2011) also highlight key concerns of privacy and integrity around the use of social media. Because these new approaches are often more accessible and unpredictable (Beetham \& Sharpe, 2013), Hedberg (2011) argues the need for more than successful mastery of technology, but expert collaboration, successful experience orchestration, and the creation of an on-going support community.

Vrasidas and Glass's (2005) study identified a conservative education culture that is slow to reform policy, curriculum and assessment, with a heritage of resistant teachers. Also, operating in a contextual environment known for: a tradition for sometimes perverse or limited incentives and time to investigate and integrate new technology into the curriculum; an insufficient infrastructure; and meagre on-going support. Al-Bahrani and Patel (2015) identified additional drawbacks, including over-utilisation of mobile devices in classrooms, privacy issues, additional time consumption due to easier access to faculty, and the additional effort required to bring unfamiliar students up to speed with the platform(s).

Research by Hedberg (2011) highlighted that, to a fearful and technologically inept instructor, challenging, new technology creates anxiety, requiring teachers to adapt to a more flexible sense of self. Beetham and Sharpe (2013) identified that successful technological implementation was seen by faculty as a long-term project aligned with the staff's own perceptions of their evolving expertise and confidence. This requires, as Rambe and Bere (2013) argue, a transformation to the role of lecturer, morphing from being an expert knowledge (and skill) instructor to an all-embracing, on-demand guide, mentor and facilitator. Echoing a recurrent theme in the literature, responsibility for the development of 
faculty social network capability is something Richmond, Rochefort and Hitch (2011) believe lies firmly with the educational institution.

\section{Literature review summary}

This exploration of the literature sought to understand to why social media based pedagogic enrichment often fails. The insight gleaned is rather contrary to the perceptions about insular, born digital Gen Z's being comfortable interacting in a virtual environment. Surprisingly, it rather paints a picture of resistant students who appear reluctant to use social media for formal, active learning, preferring a more passive, free riding, lurking role, who voice concerns pertaining to privacy, integrity and the appropriation of 'their space'. There is recognition that traditional lecture- driven instruction has less efficacy, but the potential of social media to foster many-to-many, transformational experiences through guided learning has yet to be realised, with limited evidence supporting any material pedagogic shift. In a fast-changing digital field, it is difficult for educators to retain subject currency, a challenge that is exacerbated by generational gaps between head-in-the- sand instructors and digitally native learners, each with different expectations. There is also recognition of the need to ensure that university students are well prepared for the workplace, which likely requires a new sense of pedagogic self, and an expertise shift away from instructor towards guide, mentor and facilitator.

\section{Methodological approach}

Convenience sampling was used to identify a diverse group of 11 marketing and marketingrelated lecturers and senior lecturers from across UK and ten students from a medium- sized research-focused English University. Students from one of the author's second year undergraduate digital marketing classes were invited to volunteer to contribute their opinions by participating in a one-on-one informal interview. Participation came predominantly from the most engaged, high-performing students. Academic participants, drawn from the author's personal connections made at national pedagogic and marketing conferences, were selected for their extensive (decade or more) instructor experience and for their recent experience of digital tool experimentation. Marketing was considered to be an optimal discipline for research because of the importance and centrality of both digital and social media within its contemporary, dynamic curriculum. Individual interviews were the chosen research methodology over focus groups because they can be more effective at generating widerranged themes (Guest et al., 2017). Due to the potential sensitivity of the topic, all respondents were promised and given full anonymity. A comprehensive participant briefing was undertaken by the author prior to commencing all the inteviews, covering all the required ethical disclosures and informing interviewees of the purpose of the research. For those who expressed an interest, the researcher shared a short summary of the secondary and interim primary research findings immediately after the formal interview had been concluded. Faculty participants were invited to share their own experience of digital innovation failures over email but the majority opted for a recorded interview with the author that took place either in person or over the telephone. The ten students, who had all studied digital marketing with the author and responded to a social media invitation, participated in an in-person semistructured interview that explored their perceptions of social media and digital tool use in 
their university learning journey. McGrath, Palmgren and Liljedahl (2019) highlight the importance of developing a rapport and effectively establishing comfortable, trusting interactions between the interviewer and interviewees in qualitative research. The research methodology was designed and implemented in accordance with the author's institutional ethical research policy. Khazaal et al. (2014) note that caution is needed when interpreting studies using self-selecting respondents. This modest scale, qualitative and limited research was never designed to offer up scalable, representative findings. Student participants were given a book voucher by way of compensation for their contribution, in line with contemporary custom for equity and non-exploitation of immaterial labour. Interviews usually lasted between 20 and 40 minutes. Interviews were transcribed manually by the author using an iPhone and wordprocessing package and then analysed thematically, using coloured highlighters and Post-It notes. By linking repeated ideas presented by students and faculty, the emergent themes were then used to aggregate, analyse, and present the research findings.

\section{Findings and discussion}

Results are presented in two main sections, starting with analysis of the staff interviews and concluding with insights from the student research.

\section{Staff respondent results and discussion}

Reflecting on wide and deep experience across more than ten universities and drawing on a broader understanding of the social media definition (Davis et al., 2012), staff respondents mentioned a number of tools they had experimented with including: blogs, Quizlet, Socrative, Kahoot, Facebook, Google hangout, YouTube, Polleverywhere, Tableau, Photoshop, Google Analytics, Instagram, LinkedIn, Pebblepad, Thales reading lists, and Padlet. Faculty interviews were deliberately concentrated on exploring social media failures and the results are presented using four main themes that evolved from the author's coding process, using coloured highlighter pens and dynamic systematisation of summary Post-It notes. The first three: resistance and the fear of failure, additional preparation time, and limited technology support were found to be in line with Vrasidas and Glass's (2005) findings, familiar change management problems that generations of educational technologists have previously encountered. Given that social media innovations in UK Higher Education are often adopted as non-mandatory, blended enrichment, more unexpected findings are presented in the fourth staff theme, which considers the failure of student engagement.

\section{Student and staff resistance and the fear of failure}

One of the primary causes of staff resistance was identified by several respondents as the fear of failure, evidenced by this example telling insight; "Students assume if you don't know what you are doing, they think you are not a very good teacher". Staff were unsure of what technology to use, were fearful of it not working and being made to look stupid, together creating apprehension that had been burnt into their memory by their own and/or colleagues' bad experiences. These findings were very much in line with Hedberg (2011). Operating in an increasingly marketised UK Higher Education environment, with high fee paying and demanding students, academics perceived that they were not afforded the chance to fail in 
delivery, they "just had to get it right first time". The fear of complaining behaviours from students was a strong sentiment that came out of several of the interviews, because "if anything went wrong", some students were likely to "act as dissatisfied customers, running, screaming and fussing to figures of authority".

One academic was quite emphatic in stating that, in their opinion, "not all digital native students were actually that tech savvy", struggling when "an application is not as intuitive as Snapchat" and "finding new technology to be really scary". This perspective aligns with Selwyn's (2012) idea of student competencies, spanning a continuum from technophobe to highly skilled professional. Students, it was said, "often possess heavily mediated online digital footprints" and yet they "did not ask questions, did not want to look foolish or a swot asking too many questions in class forums". One particularly academically gifted and selfassured student expressed their anxiety; "you don't want to be flamed by other students in a big forum", highlighting a preference for communicating in smaller, closed groups "where you know everyone". For example, when a group of first years were asked to create a professional job search profile and begin building a network in LinkedIn, some students did not know what LinkedIn was, and the idea of creating a professional persona was an "alien concept to them". It transpired, in follow on questioning, that students were acutely worried that they would "look bad in ten years' time" and had extreme anxiety about "not knowing how to interact" in an adult, business-facing application. One faculty highlighted that this sentiment echoed "social media warnings from their schools and wider media coverage of individuals being called out for undeletable comments and opinions published by their younger and less mature selves". The media regularly carries stories of individuals being "rebuked or worse for historic social media posts".

Twitter, the micro-blogging service that is "popular for its breaking news, community exchanges and political arguments", offers an open text-focussed discussion forum, which can provide a degree of anonymity through self-created user names (dubbed 'handles'). There was a perception by three academic respondents that Twitter use was "popular with some faculty, but for research purposes rather than teaching in class". Several academics highlighted their use of the tool for signposting industry content to students; however everyone reported very limited engagement. Generally, Twitter was not considered to be successful as students were reluctant to learn a new app, and the consensus amongst academic respondents was that the majority of the student body did not end up following faculty accounts, experience that contradicts research by Junco et al. (2011) and Lowe and Laffey (2011). One respondent described their Twitter experiment as "an absolute disaster" and noted several students turned their phones over and flat refused to participate, murmuring "I'm not doing this" demonstrably, citing concerns about being found out at a job interview later in the week. Students, it seemed, did not "appreciate the opportunity to impress potential employers" by crafting a professional social media presence that "highlighted their ability to demonstrate their marketing prowess" and present themselves as "stand out, interesting thinkers". 


\section{Time investment for slick delivery}

Multiple respondents highlighted the "time and effort" usually required to experiment with even straightforward new social media tools. They signalled that there was often "an awful lot to learn with new technologies to be confidently slick in integrating it into classroom delivery", in agreement with Munoz and Wood's (2015) findings. Evaluating the effort and return, it was just often considered to be "easier not to innovate", not a case of laziness, just "pragmatic resource prioritisation". This issue was not reserved only for faculty, one lecturer, having set a six-minute YouTube video creation project, met resistance from students who felt they had to spend excessive time developing their film production skills. Activity that the students felt lay well outside the credit bearing scope of the assessment, evidenced by this response; "I'm a business student, not a media arts student, you know!". The lecturer reflected that the non-credit bearing effort required to travel down the technology learning curve somewhat detracted from the assignment content, and noted that "where new technical skills are required, these should be included in the learning hours expectation and rewarded explicitly in the marking criteria".

Three respondents shared similar stories related to inexperienced experimentation with word cloud tools (such as Answer Garden and Polleverywhere) that allow students to write what they want, anonymously, onto the projected screen with the objective to encourage wider, inclass engagement with open questions. In some, but not all, instances several students wrote offensive content, including sexist remarks and used inappropriate language. Platform anonymity, whilst potentially overcoming student fears of being flamed or shamed, was found to be problematic, notably with less mature students, and highlighted issues of effectively policing boundaries, as identified by Beetham \& Sharpe (2013). One staff interviewee decided "never to use the tool again", whilst another lecturer said "I went home and cried". Yet another saw students' post "super safe, sweet platitudes", resistant, task avoidance behaviour that sought to "avoid embarrassment, politely". These examples illustrate situations where subversive student groups failed to address the set task meaningfully, resulting in a sub-optimal learning engagement that generated faculty feelings of failure. Reflection on these dissatisfying outcomes identified inexperience and a lack of sufficient preparedness as key factors. Innovative faculty often had missed crucial, real time filter functionality to block frivolous participant contributions and establish firm ground rules upfront with students, to establish a shared understanding of what constituted appropriate responses. These findings align with Vrasidas and Glass's (2005) research.

\section{Technical challenges and a perception of limited support}

Some staff discussed their often positive engagement enhancing experience, using clickers, physical and virtual devices, that allowed students respond to lecturer questions (often using multiple choice or numerical inputs) and see aggregated, anonymised cohort responses on a shared screen. It was found, however, that there were issues with the logistics of physical clickers, "not being delivered to the learning space in a timely fashion", hub connectivity, insufficient working units, and "late arriving students not picking up devices". Additionally, with virtual clickers (students' own mobile devices) occasionally not working because of low battery power or a full memory. Aligned with Fose and Mehl (2007), one lecturer commented 
that whilst gamification could "energise the learning environment and bring a sense of fun", some students she had worked with felt polls and quizzes were "trivial and rather beneath them". Here, follow-on discussions highlighted a perception that US College programmes might typically benefit from larger, multi-person teaching teams. In-class teaching assistants can support their professors who were able to "triage technical set up issues", but this is not typical in the UK

Higher Education sector, where solo staffing is the norm. UK academics are usually required to manage technology niggles, often necessitating individual attention, whilst also trying to orchestrate an effective learning rapport with the whole student body. This was identified as being "significantly more demanding than merely demonstrating tool competence" as identified by McLoughlin and Lee (2010). Where leaders of large modules were responsible for coordinating other staff members to implement innovations, with diverse, individual capabilities and motivations to embrace novel ways of working, the challenges of teachingthe-teacher multiplied further, with a "pragmatic tendency to level down rather than up".

Many respondents indicated that they did not know who to ask for help and advice when investigating social media and wider digital innovations. Several identified a lack of trust in the technology infrastructure to be able to deliver learning encounters with confidence, and difficulties in getting specialist software loaded onto campus computers for students to access in class and beyond; "we just haven't supported it properly". A common refrain was noted, that often, learning technologists were too technology-led, and not teaching-led. An interesting idea was highlighted by several respondents, who indicated that they tried to use a pedagogy (not tech) first orientation, rather than doing something digital for the sake of doing it; "I try to think what tech will solve my problem or augment my teaching".

Not all students have access, or choose to have access, to every social media tool, for example Chinese students were found to prefer Weibo over Facebook, which is blocked in China. This problem of non-universality is a significant issue, with staff bound to ensure equity of access, but challenged by finding tools that work for everyone without taking onerous responsibility for learning to use multiple tools and duplicating activities across multiple platforms.

\section{Disappointing student engagement}

When digital tool use forms part of a mandatory student assignment, engagement issues were less apparent. Most of the examples of failure discussed by faculty members involved enrichment experimentation (Johnson \& Jones, 2010) that was not obligatory, often part of a deliberate pedagogic design, where students were given the choice to participate or not. Implementing technology-based innovations in high stakes, summative assessments was considered to be "ultra-high risk". However, in something of a Catch-22 situation, students were found to be all too often "unwilling to engage in tasks unless they were mandatory", faculty respondents noted that take up was "significantly compromised unless course credit was attached". One example, of a student-authored blog, was found to drive engagement only if access was required during class, "if you expect to see comments beyond class, it doesn't happen", resulting in advice not to "bother with long blogs, students want short things". 
Disappointing iterations of innovations where teacher effort was high but accompanied with low student engagement were commonplace. Unsurprisingly therefore, several respondents expressed feeling rather jaded. For example, one lecturer spent a whole day creating a 30minute video to replace a snowed off lecture, to find that students had "not watched the video". Two respondents gave the example of introducing the Talis online reading list system, populated with a range of useful content, including video tutorials, but again found "very low student take up", perhaps because there were just too many assets on the virtual learning environment, and due to "confronting students with too much diverse, whizzy tech".

Facebook use was found to be a quite negative experience over all. It was felt by several respondents that students conceive "Facebook as their place and did not want academics lurking or moving into that space". Reflections such as, "I don't think they would interact with me to be honest if I was in a Facebook group" and "I've been astonished, shocked and horrified that nobody engages with my professional Facebook page", typifying faculty perspectives, but in line with Al-Bahrani and Patel's (2015) suggestion that boundarybreaking Facebook is more intrusive.

Instagram was only mentioned by a single respondent who found it engaged induction students, using a self-guided outdoor treasure hunt that required students to capture images that were shared by the class using a hashtag. But, in a follow-on encounter, only two or three students participated from a cohort of 100. In agreement with McLoughlin and Lee (2010), one faculty respondent cited student boundary feedback; "That's my space, I don't want you in this room" and "I don't want to post that". Many students, it seems, did not want to associate their studies with their online personas, because it might downgrade their "cool factor" and "peer reputation", and result in "lost followers".

\section{Student interview findings}

During interviews, students were able to recall unaided a wide range of digital and social media tools utilised in their teaching and learning including Moodle forums, email, Google docs, Twitter, LinkedIn, Facebook, Whatsapp and even one mention of the dating service Tinder. However, examples, although varied, were sparse, rather confirming Tess's (2013) view that pedagogic social media use has yet to be widely adopted across the curriculum, albeit drawing only on the experience of students from a single institution. Student interaction in social media appears to concentrate on "sharing humour" and "information about assessments". Many respondents divulged their predilection for lurking, Selwyn's (2012) one-way passive content consumption behaviour, watching but not posting. However, analysis of interview transcripts did not support Blankenship's (2011) omni-present social media assertion. Instead students, reflecting their particular institutional experience, expressed views such as; "we don't use social media that much in our course", and "platforms are not the place for university learning", but also providing some contradictory sentiment; "some platforms are for learning, there is everything on Facebook, interesting articles and documents".

Despite the ubiquitous rhetoric that digital native students are always connected, respondents opined; "I don't really go there [Facebook], I don't really use it that much anymore", "I feel 
it's dead now, people are on it, it's just not the space for me and most of my friends", "not everyone is on Facebook", and not all group members "have Facebook or claim they can't find it". This evidence tends to support the widely reported youth trend away from Facebook and towards Instagram and other more visual platforms (Alhabash \& Ma, 2017). Interviewed students claimed to use social media to collaborate with each other and for assigned tasks, but there were alternative perspectives also presented, for example; "I'm a private person,... I am not $100 \%$ comfortable using social media, I prefer to ask course mates in person", evidence that highlights that participation is not always willing or congenial, reinforcing Munoz and Wood's (2015) view. The reason for low levels of voluntary engagement with instructorfacilitated social media was attributed to feelings of anxiety, students did not want to "trip up", "say something wrong", or "offend someone".

Discussing a failed experimental engagement with Twitter, students suggested it was caused by peer anxiety, nervousness and a lack of familiarity with the app, one respondent believed students were shy and did not want their tweets to be read out loud in class, perhaps because social media is "more comfortable when it's just students". When asked to develop a LinkedIn profile as first years, notably with no course credit, several respondents indicated that they did not complete the voluntary task. Having then not used LinkedIn for two years, one job-hunting finalist found it to be "quite cold, but I now like it, it's so professional you hardly see an emoji". Student inhibition, to be wary or cautious, might be explained by the observation that in- person embarrassment fades over time, but "online things are permanent, even if you delete it after three seconds, it's still there, someone may have taken a screen shot and shared it with their friends. If you post something there is no going back" - echoing Moran et al's (2011) integrity and privacy concerns. Educators should note student heterogeneity, in line with Selwyn's (2012) inequitable socio-demographic findings, and crucially that not every student is active in every platform, and that many are very cautious about their privacy and profoundly risk averse.

\section{Students on peer connectedness}

In discussing the digital tools that marketing respondents used amongst themselves for group work, students cited Facebook Messenger, and Google docs (valued for its simultaneous, virtual editing) most often, with Whatsapp and email also less frequently mentioned. Facebook Messenger, which has meeting coordination and document sharing functionality, was a "first port of call" because it was easy to find group members by name, whilst Whatsapp required more sensitive sharing of telephone numbers, which was not always desirable, again echoing Moran's (2011) concerns for privacy and integrity. Wider social media groups were used mainly for "questions about exams", "selling used books" and "flat shares", with several respondents stating that they had "become tired of the banal group chat" found there.

When asked why students did not engage more in the more public, student-facing social media environments, explanations included that students did not want to: "share with people they don't know", "look stupid and be made fun of", "be judged on posts", "be the only one posting", and finally "be flamed or called out". In describing the finalist's 200-member strong, Facebook Messenger group (perceived to be a faculty free zone), one participant believed it to have been "quite fundamental in helping many students pass their degree" 
thanks to "effective and timely information sharing". When a lecturer might take two or three days (well within the institutional response time policy) to reply to an emailed question, crowd sourcing a problem to peers might take just ten minutes. Clearly signalling a 'be here now' generational preference for instant gratification from a less authoritative source over the perhaps more veracious, but less instantly responsive faculty. The popularity of the Messenger application is potentially due to its user interface which "feels like you are replying to friends, and then you are like, OMG, there are actually 200 people in this chat, but it feels a lot smaller".

\section{Student - staff connectedness}

Students voiced uncertainty around "how they should interact" with faculty, unsure of the social etiquette. University adult learning marks a transition from school, where sensible child protection rules prohibited pupil- teacher friendships. "Social media feels like a lightly policed space" and connecting with a lecturer, some said, can make it "feel like those boundaries are put back" according to Beetham and Sharpe (2013). Respondents also highlighted student apprehension of "contradicting staff opinions" and anxiety around the "potential consequences" of a memorable disagreement. Supporting Elliott's (2011) finding that students valued an enduring, personal relationship with their university educator, several, albeit self-selected, respondents expressed that they liked connecting with staff on social media, choosing LinkedIn for acquaintances but linking on Facebook only with faculty who they found a 'connection' with. Although one student was worried about the "potential negative perception" that could be created by their "missed class again" posts. In accordance with Hargittai (2008) there were, however, several opposite perspectives voiced, such as: "my other half categorically won't connect with staff" and "I don't connect with members of staff', perhaps also challenging the utility of Lohman's (2016) contention that professors are expected to utilise social media tools as a matter of course in their teaching. Some students stated that they "only accepted invitations to connect from staff in LinkedIn", which was considered to be the more appropriate venue for teacher interactions. One participant felt flattered to be invited, as they felt it recognised their class contribution, whilst another student had strategically connected with three staff members to be able to "keep in touch for their future career" and having "someone to count on" in the final year. Another more confident student said "I connect actively with staff on LinkedIn, particularly where there is a good connection, it is easy to ask questions, email is too formal", highlighting perhaps an uncomfortable impasse, Roblyer et al. (2010) noted staff preference for traditional platforms like email.

Perspectives on students connecting with faculty over Facebook were significantly less positively evidenced, reinforcing Taylor et al.'s (2012) findings, by refrains such as: "no, I don't mind students, but not teachers, it's about my family, my holidays", "awkward party pictures" and "it's a lot more personal, fun and photos, drunk Friday nights out". However, in accordance with Dearbone (2014) and Elliott (2011), some respondents were more open, interested to discover teachers as they 'really' are, explaining that for them it very much depended on the nature of the relationship with the teacher. One student opined that "the relationship had to go with the social media" and they found it easier to talk via Facebook than email, "that's more my generation". The majority of interviewees were not active 
Twitter users, finding the platform "difficult to sign up for and use", an outcome that is very much in harmony with the new technology resistance observed by Munoz and Wood (2015). Twitter was, however, found to be useful for breaking down barriers, following guest speakers, offering interesting content that "wasn't super cringey or too, like, in our faces" and considered best for a constant pour of information for assignment assistance. Evidence found in this study supported the divergent perspectives on student appetite for the academic appropriation of social media channels (spanning Taylor et al., 2012 to Dearbone, 2014) but perhaps at the same time supporting Thayne and Cooper's (2014) contention that social media can be a trust and bond enhancing catalyst for some.

One commuter student found the novel, one off virtual lecture week, which utilised the virtual discussion forum, to be a very positive experience, suggesting that "higher than usual levels of student engagement were observed". They believed this was a function of the computer-mediated 'shy boundary' which allowed "brave screen warriors to take their own time and participate with an effective embarrassment filter". Students were unanimously categorical in their rejection of both Snapchat and Instagram for staff connections, both recognised as being "just not the place", "I can't see anything professional" and "it's just pictures" supporting McLoughlin and Lee's (2010) notion of resistance to the invasion of their own space.

\section{Conclusion: Why do digital teaching innovations fail?}

In seeking to understand why digital pedagogic innovations fail, four themes emerged from staff interviews; resistance and the fear of failure, the need for additional preparation time, limited technology support and disappointing student engagement. Essentially research insight that presents a picture of digital pedagogic innovation, from a staff perspective, as a high stakes, time intensive activity that is insufficiently supported by both universities and the student body. Themes identified from trying to understand student perspectives on digital tool and social media use at university were purpose, boundaries, anxiety and social media preferences. Students ascribed diverse value and notably purpose to different platforms, identifying some platforms as private spaces for close friends and family only, where faculty were not welcomed. Many were not wholly convinced about the merits of using social media for formal university learning, although a variety of tools were found to be helpful for beyond class group work collaboration.

Whilst comfortable engaging with faculty in less intrusive (and less popular) professional applications, such as Twitter and LinkedIn, privacy boundary concerns were identified by many in Facebook and unanimously with Snapchat and Instagram, notably when used for sharing more personal content. Social anxiety concerns highlighted included: the perceived fear of hostile responses, and judgement from peers, alongside concerns about the risk of future, career limiting embarrassment caused by everlasting posts. The research also highlighted that not every digitally native student was present and/or active even in the more popular social media platforms. Put together, these themes might reinforce Selwyn's (2012) finding of divergent perspectives and perhaps this nuanced complexity helps explain the dearth of effective digital pedagogic strategies that has been signalled by Roberts and Micken (2015). 
An important insight from this research is the need to consider the student body not as a homogeneous digital group (Hargittai, 2008), and to avoid the unhelpful narrative of technophobic instructors educating tech-savvy digital natives. But, rather as Selwyn (2012) highlights, to embrace diversity and the value in consensual collaboration, particularly in relation to the choice of social media platform(s) and by offering multi-channel, opt-in choice. Empowering students to choose how and where they engage recognises the importance and heterogeneity of public-private boundaries, and the degree to which each individual student is more open, or inhibited, to contribute their ideas in a 'forever' social media record.

Marketing instructors may wish to consider the potentially negative, controlling impact of their own presence in student- facing social media and how this might inhibit student learning (Rambe \& Bere, 2013). Operating as a guide-on- the-side lecturer (King, 1993), it may be appropriate to foster self-directed groups who make their own, private choices for collaborative social media spaces located comfortably beyond the gaze of faculty. 


\section{References}

Al-Bahrani, A., \& Patel, D. (2015). Incorporating twitter, instagram, and facebook in economics classrooms. The Journal of Economic Education, 46(1), 56-67.

Alhabash, S., \& Ma, M., (2017). A Tale of Four Platforms: Motivations and Uses of Facebook, Twitter, Instagram, and Snapchat Among College Students?. Social Media+ Society, 3(1), 2056305117691544.

Beetham, H., \& Sharpe, R. (2013). Rethinking pedagogy for a digital age: Designing for 21st century learning. Routledge.

Blankenship, M. (2011). How social media can and should impact higher education. The Education Digest, 76(7), 39-42.

Buzzard, C., Crittenden, V. L., Crittenden, W. F., McCarty, P. (2011). The use of digital technologies in the classroom: A teaching and learning perspective. Journal of Marketing Education, 33, 131-139.

Carr, N., (2010, May 25). The web shatters focus, rewires brains. Wired. https://www.wired.com/2010/05/ff-nicholas- carr/

Crittenden, V., \& Crittenden, W. (2015). Digital and social media marketing in business education: Implications for the marketing curriculum. Journal of Marketing Education, 37(2), 71-75.

Dabbagh, N., \& Kitsantas, A. (2012). Personal Learning Environments, social media, and self-regulated learning: A natural formula for connecting formal and informal learning. The Internet and higher education, 15(1), 3-8.

Davis III, C. H., Deil-Amen, R., Rios-Aguilar, C., \& Gonzalez Canche, M. S. (2012). Social media in higher education: A literature review and research directions. The University of Arizona and Claremont Graduate University, 8.

Dearbone, Ryan, "Relational Development, Self-Disclosure, and Invasion of Privacy: College Students and Teachers as Facebook Friends" (2014). Masters Theses \& Specialist Projects. Paper 1349. http://digitalcommons.wku.edu/ theses/1349

Duffy, K., \& Ney, J. (2015). Exploring the divides among students, educators, and practitioners in the use of digital media as a pedagogical tool. Journal of Marketing Education, 37(2), 104-113.

Elliott, A. (2011). Equity, pedagogy and inclusion. Harnessing digital technologies to support higher education access and success. The Journal Of Community Informatics, 6(3), 1-9. http://www.ci-journal.net/index.php/ciej/article/view/751

Evans, C. (2014). Twitter for teaching: Can social media be used to enhance the process of learning?. British Journal of Educational Technology, 45(5), 902-915.

Espuny Vidal, C., González Martínez, J., Fortuño, M. L., \& Gisbert Cervera, M. (2011). Actitudes y expectativas del uso educativo de las redes sociales en los alumnos universitarios. RUSC. Universities and Knowledge Society Journal, 8(1), 171- 185.

Fose, L., \& Mehl, M. (2007). Plugging into students' digital DNA: Five myths prohibiting proper podcasting pedagogy in the new classroom domain. MERLOT Journal of Online Learning and Teaching, 3(3), 277-287.

Gikas, J., \& Grant, M. M. (2013). Mobile computing devices in higher education: Student perspectives on learning with cellphones, smartphones \& social media. The Internet and Higher Education, 19, 18-26. 
Gouseti, A. (2010). Web 2.0 and education. Learning, Media and Technology, 35(3), 351-56.

Guest, G., Namey, E., Taylor, J., Eley, N., \& McKenna, K. (2017). Comparing focus groups and individual interviews: findings from a randomized study. International Journal of Social Research Methodology, 20(6), 693-708.

Haig, M. (2005). Brand failures: The truth about the 100 biggest branding mistakes of all time. Kogan Page Publishers. Hargittai. E. (2008) Whose space. Journal of ComputerMediated Communication, 13(1), 276-297.

Hedberg, J. G. (2011). Towards a disruptive pedagogy: Changing classroom practice with technologies and digital content. Educational Media International, 48(1), 1-16.

Hirsch, E. (2012). The paradox of design entrepreneurship: are you a risk voyeur?. Design Management Review, 23(3), 86-87.

Johnson, K. A. (2011). The effect of Twitter posts on students' perceptions of instructor credibility. Learning, Media and Technology, 36(1), 21-38.

Johnson, P. M., \& Jones, S. K. (2010). Beyond the banner: Teaching powerful creative techniques in digital marketing. Journal of advertising education, 14(1), 7-14.

Junco, R., Heibergert, G. \& Loken, E. (2011). The effect of Twitter on college student engagement and grades. Journal of Computer Assisted Learning, 27, 119-132.

Karl, K. A., \& Peluchette, J. V. (2011). "Friending" professors, parents and bosses: A Facebook connection conundrum. Journal of Education for Business, 86, 214-222.

Kassens-Noor, E. (2012). Twitter as a teaching practice to enhance active and informal learning in higher education: The case of sustainable tweets. Active Learning in Higher Education, 13(1), 9-21.

Khazaal, Y., Van Singer, M., Chatton, A., Achab, S., Zullino, D., Rothen, S., ... \& Thorens, G. (2014). Does self-selection affect samples' representativeness in online surveys? An investigation in online video game research. Journal of medical Internet research, 16(7), $1-10$.

King, A. (1993). From sage on the stage to guide on the side. College teaching, 41(1), 30-35.

Lee, M. \& McLoughlin, C. (2010). Web 2.0-based e-learning.

Hershey PA, Information Science Reference

Lewis, K., Kaufman, J., \& Christakis, N. (2008). The taste for privacy: An analysis of college student privacy settings in an online social network. Journal of Computer-Mediated Communication, 14(1), 79-100.

Lohman, L. L. (2016). Generation ZZZ: Keeping students engaged in the classroom (beyond their phones!). Marketing Management Association Annual Conference Proceedings 183-184.

Lowe, B. \& Laffey, D. (2011). Is Twitter for the birds? Using Twitter to enhance student learning in a marketing course? Journal of Marketing Education, 33(2), 183-192.

McGrath, C., Palmgren, P. \& Liljedahl, M. (2019). Twelve tips for conducting qualitative research interviews. Medical Teacher, 41(9), 1002-1006.

McLoughlin, C., \& Lee, M. J. (2010). Personalised and self regulated learning in the Web 2.0 era: International exemplars of innovative pedagogy using social software. Australasian Journal of Educational Technology, 26(1), 28-43.

Moran, M., Seaman, J., \& Tinti-Kane, H. (2011). Teaching, learning, and sharing: how today's higher education faculty use social media. Babson Survey Research Group. 
Muñoz, C. L., \& Wood, N. T. (2015). Update status: The state of social media marketing curriculum. Journal of Marketing Education, 37(2), 88-103.

Prensky, M. (2001). Digital natives, digital immigrants part 1.

On the horizon, 9(5), 1-6.

Roblyer, M. D., McDaniel, M., Webb, M., Herman, J., \& Witty,

J. V. (2010). Findings on Facebook in higher education: A comparison of college faculty and student uses and perceptions of social networking sites. The Internet and higher education, 13(3), 134-140.

Rambe, P., \& Bere, A. (2013). Using mobile instant messaging to leverage learner participation and transform pedagogy at a South African University of Technology. British Journal of Educational Technology, 44(4), 544-561.

Richmond, N., Rochefort, B., \& Hitch, L. (2011). Using social networking sites during the career management process. In higher education administration with social media (pp. 147- 164). Emerald Group Publishing Limited.

Roberts, S. D., \& Micken, K. S. (2015). Marketing digital offerings is different: strategies for teaching about digital offerings in the marketing classroom. Journal of Education for Business, 90(2), 96-102.

Selwyn, N. (2012). Social media in higher education. The Europa world of learning, 1-10.

Shaltoni, A. M. (2016). E-marketing education in transition: An analysis of international courses and programs. The International Journal of Management Education, 14(2), 212218.

Sharples, M., de Roock, R., Ferguson, R., Gaved, M., Herodotou, C., Koh, E., ... \& Weller, M. (2016). Innovating pedagogy 2016: Open University innovation report 5. Institute of Educational Technology, The Open University.

Siemens, G., \& Weller, M. (2011). Higher education and the promises and perils of social network. Revista de Universidad y Sociedad del Conocimiento (RUSC), 8(1), 164-170.

Taylor, S. A., Mulligan, J. R., \& Ishida, C. (2012). Facebook, social networking, and business education. American Journal of Business Education (AJBE), 5(4), 437-448.

Tess, P. A. (2013). The role of social media in higher education classes (real and virtual)-A literature review. Computers in Human Behavior, 29(5), A60-A68.

Thayne, M. \& Cooper, G. (2014). Digital learning environments and collaborative pedagogy: Media Culture 2020. Creating the difference: Proceedings of the Chi Sparks 2014 Conference, pp. 104-107.

Thomas, M. (2011). Technology, education, and the discourse of the digital native. Deconstructing digital natives: Young people, technology, and the new literacies, 1-11.

Tuten, T., \& Marks, M. (2012). The adoption of social media as educational technology among marketing educators. Marketing Education Review, 22, 201-214.

Vrasidas, C., \& Glass, G. V. (2005). Preparing teachers to teach with technology. IAP. 


\section{Reverse Bloom: A new hybrid approach to experiential learning for a new world}

Journal of Education, Innovation and Communication (JEICOM) 30-45

Vol. 2. Issue 2, December 2020 DOI: $10.34097 /$ jeicom-2-2-Dec2020-2

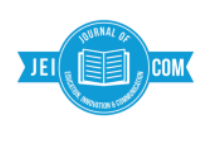

Dr Arthur W Shelley ${ }^{4}$

\begin{abstract}
Bloom's Hierarchy of learning has been the foundation of formal teaching and assessment practice since the mid 1950's. This has resulted in higher-quality education outcomes, more consistency in delivery, and better teaching practices. However, mainstream teaching practices and teacher training have focused on the Cognitive domain, with less focus on social development (except for some societies and non-mainstream institutions). There has been little emphasis on the two other domains for comprehensive learning, which Bloom's colleagues identified as the Psychomotor and Affective domains. These two less used domains highlight the skills and social aspects of being able to influence others and apply the learning in practice to generate value. The imbalance between the three is critical because all three domains play a role in being a competent professional and a contributing member of society, based on the capabilities built in their learning experiences.

This paper shares three key new contributions to the learning literature that help address this imbalance: The "Reverse Bloom Learning Framework" (RBLF), a set of principles to guide learning facilitation through the RBLF, and some insights on design of inclusive learning activities (including provision of deeper feedback for better reflection and higher quality learning outcomes). Together these three elements of progressive learning can enable a more balanced approach to learning at all levels. The RBLF includes all three of Bloom's domains in iterative social learning experiences and reverses the traditional order of Bloom's learning elements. The author suggests this more inclusive and comprehensive approach enables facilitation of more collaborative learning and that this will generate more competent, confident and capable graduates, who are better equipped to interact in our modern challenging workplaces and our wider world.
\end{abstract}

Keywords: experiential learning, education, knowledge flow, capability development, framework, co-creation, collaboration.

\footnotetext{
${ }^{4}$ Founder, Intelligent Answers, Senior Industry Fellow, RMIT University, School of Property, Construction and Project Management, Melbourne. Email: Arthur.Shelley@RMIT.edu.au
} 


\section{Introduction}

There are many approaches to learning, and these have reflected the nature and expectations of society at that time. Highly disciplined content-based approaches are the common and traditional method adopted widely in formal education institutions in most parts of the world. However, with changes in society and technology, new approaches to teaching and learning have emerged. All of these have their place with differing strengths and weaknesses. Some of the approaches that have gone beyond the idea of rote learning of facts and figures, have interesting characteristics worth discussing in this introduction to set some context for the new framework being introduced in this paper.

Despite their differences and contexts, many learning approaches have been influenced by the concepts of Bloom's Hierarchy (Bloom 1956), especially the modified version of the Cognitive Domain of this framework (Anderson et al 2001). Gershon (2018) highlighted that the insights being used today for learning and assessment are primarily drawn from the Cognitive domain. The other two domains discussed in the original forums, the Psychomotor (Skills aspects) and Affective (Social/Emotional aspects) have been progressively less used, possibly because detailed work on these two domains were not fully published as planned. It could also be that the shift in society towards more "scientific" (read quantitative and measurable) approaches were being preferred in the second half of last century. One issue highlighted early by Dewey (1938) with quantitative, content focused education was this it emphasises competition at the expense of collaboration. Whilst being competitive is an important success factor in life, the learning to collaborate is becoming a more important capability in our modern world (Freeth \& Caniglia, 2020; WEF 2020a).

There are some exceptions that engage in more holistic education, such as Steiner Education (Edmunds, 2004) and Montessori Method (AMI, 2020a), although these are generally considered as "alternative approaches". More recently, there has been a trend towards more holistic education (Miller et. al., 2018), with the reintroduction of experiential and social aspects into some mainstream curricula. For example, in Victoria, Australia (Victoria Dept Education \& Training, 2020) and Finland (Zilliacus, Holm, \& Sahlström, 2017) learning in real context with collaborative learning and social development are being practiced to a greater extent. This is a positive trend that this paper seeks to accelerate.

Mainstream approaches to education seem to have followed this trend, with more measurable and objective assessments being made and more standardisation of learning and teaching curricula. Whilst this has elevated the academic standards of education, it has also biased the mainstream education processes away from generating students who develop a balance of academic (theoretical cognitive) and social and life skills (psychomotor and affective capabilities) (Robinson \& Aronica, 2016). Although there is some shift towards inclusion of social elements in some places (for example Victorian Department of Education and Training 2020), it will take time to get sufficient balance across the domains.

There are examples of increasing awareness of the importance of social approaches in learning for professional workplaces. The future skills report generated by World Economic Forum (WEF, 2020a) highlights the growing importance of soft skills for success. One good example in practice is Novartis $(2018,2019)$, where the CEO, Vas Narasimhan, launched the collaborative teams initiative tagged as Unbossed. Novartis claims the program is stimulating innovation and speed to market through faster learning. They believe these outcomes have 
been generated because increased trust and social interactions enable greater leverage of diversity and this accelerates generation of new ideas. A number of public videos are available online describing the initiative and its foundations.

The World Economic Forum has recognised the importance of social capital that people bring to effective professional practice. Their report recommends revaluing, and consciously accounting for, the value this adds in the new work environment (WEF, 2020b). This is consistent with the ideas on Expansive Education developed by Engeström and Sannino (2016), which highlights quality applied learning builds both transformative agency and the ability in learners to form new theoretical concepts in practice in future social contexts. Expansive education techniques have been successfully deployed in health care as Simulation Based Education, where a depth of knowledge is needed to act in life impacting situations (Burton \& Hope, 2018).

An insightful quote from Edward de Bono is applicable in this context: "EBNE - Excellent, But Not Enough". It reinforces that knowing theories is a good thing. However only knowing is insufficient to optimise value. Learners benefit through practicing their understanding in various contexts and further refine them to perform as competent lifelong learning professionals. These examples reaffirm the author's belief that optimal future education is about opening minds and building confidence to act in uncertainty. This contrasts with content-based traditional education that focuses on filling minds with known content. The education experiences should develop the learners at the appropriate level across all three capability areas of knowing (developing understanding of principles involved in the concepts), doing (application of "hard skills") and being (social, cultural and behavioural soft skills).

Engaging people to explore possibilities in socialised exchanges around real contexts is increasingly used approach for learning (Shelley 2014; Shelley \& Goodwin, 2018; AlvarezAlvarez, Sanchez-Ruiz, Ruthven, \& Montoua Del Corte, 2019). Countries with internationally recognized high education standards, such as Finland have achieved high results in the world's education ranking (NJMED, 2018; OECD, 2018). A previous exploration of these ideas explored how Applied Social Learning Ecosystems can be used to amplify the capability development across "Knowing, Doing and Being" in a postgraduate business context in practice (Shelley \& Goodwin, 2018). This article further develops that work to create a more comprehensive framework to adapt that concept to any learning context by reversing the order of thinking in the Traditional Blooms Cognitive domain hierarchy and reintroducing the other two learning domains (Psychometric and Affective).

\section{Learning Model context}

Social learning is not a new concept - it has been discussed in the literature in various forms since the work of Dewey (1938). Dewey discussed the importance of experience, experimentation and social interactions as part of purposeful learning in what he referred to as progressive education. He highlighted that students benefit from a sense of purpose in their learning and from seeing outcomes from application of what they are learning. Holistic Learning (Miller, 1997) is a term used to refer to a comprehensive development of a person intellectually, emotionally and spiritually, to become a well-rounded member of society. The term has been attributed to Smuts (1927), who was advocating for deeper and more complete 
education enabling self-actualisation. More recently, the history of, and concepts involved, in holistic education approaches have been reviewed by Miller et. al., (2018).

There is significant literature support for experiential learning approaches (Slavich, \& Zimbardo, 2012; Kolb \& Kolb, 2017). Some of these differ in the how and why it should be facilitated (Schenck \& Cruickshank, 2015) and others advocate broader curriculum to include social development in addition to the academic and cognitive aspects (Hayden \& McIntosh, 2018). Despite these emerging and ongoing dialogues, Kolb \& Kolb (2017) highlight that experiential learning has received significant support in ongoing professional development across many professional disciplines. The experiences in the medical profession support this statement (Yardley, Teunissen \& Dornan, 2012; Chamane \& Mashamba-Thompson, 2019).

This article acknowledges the depth and breadth of literature on a diversity of learning approaches being advocated, and that all have their strengths and weaknesses. This article aims to connect several of the practical insights on experiential learning into a practical framework to guide learning facilitators who wish to engage their learners through a more collaborative and social experience that is inclusive, enjoyable and beneficial. A new framework is proposed that assimilates many elements from a range of existing models to embed social, cognitive and affective aspects into the learning experience. This framework can be experimented with by educational practitioners to further evolve our options to accelerate learning and enhance learning outcomes. Although not initially designed for remote learning, the framework is adaptable to virtual learning experiences. During the period when the COVID-19 pandemic has disrupted education globally (Bonk, et al., 2020), the framework has been used to enable facilitation of experiential learning activities originally designed for face to face, by adapting interventions to make on-line learning more interactive.

The original elements of Bloom's Hierarchy (Bloom 1956) indicated that learning was built through six levels of learning in increasing richness (Knowledge, Comprehension, Application, Analysis, Synthesis and Evaluation). This suggested a process that started from a foundation of knowledge to develop understanding which enables application, from which learners can synthesise insight and evaluate the impacts and meaning of their learning. This hierarchy has been used extensively, with some others suggesting equivalent words or aligned replacement verbs for the stages. A widely accepted modified version of this framework was created by Anderson et al (2001), based on verbs and switching the order of the last two elements. This version describes the outcomes the learner was able to perform at for each of the levels, thus highlighting the actionable aspect of learning and the importance of it being learner centered. The modified hierarchy read: Remember, Understand, Apply, Analyse, Evaluate, Create). A later revision (Shelley, 2017) changed create to co-create to highlight that collaborative learning enables incorporating a range of perspectives is superior to individual development of concepts and capabilities. This paper suggests that although these latest six elements remain valid, more effective learning can be achieved by reversing their order and reintroducing the Affective and Psychomotor domains into collaborative learning experiences. 


\section{Introducing the Reverse Bloom Learning Framework (RBLF)}

Bloom's hierarchy of learning (Bloom et al., 1956; Bloom, Hastings, \& Madaus, 1971) suggests the depth of learning increases as learners progress from Knowledge, through Understanding, Application, Analysis, Synthesis to Evaluation. Versions of this have been the foundation of teaching design, delivery and assessment for half a century. Bloom originally suggested three domains: Cognitive, Psychometric and Affective. However, only the Cognitive domain remained in active use by most teachers and learning design in mainstream formal education (Gershon, 2018). This results in most learning being focused on thinking about content and assessment methods primarily quantitative. This may generate academically sound graduates, but it does not necessarily develop well rounded professionals. Figure 1 introduces a new approach, the "Reverse Bloom Learning Framework" (RBLF). The RBLF provides an alternative way of interacting and applying these elements. Rather than using these elements as a linear hierarchy to transfer existing knowledge to build capabilities, as is common in the education profession, this new framework challenges learning professionals to apply them as iterative social activities working from the top down to generate knowledge.

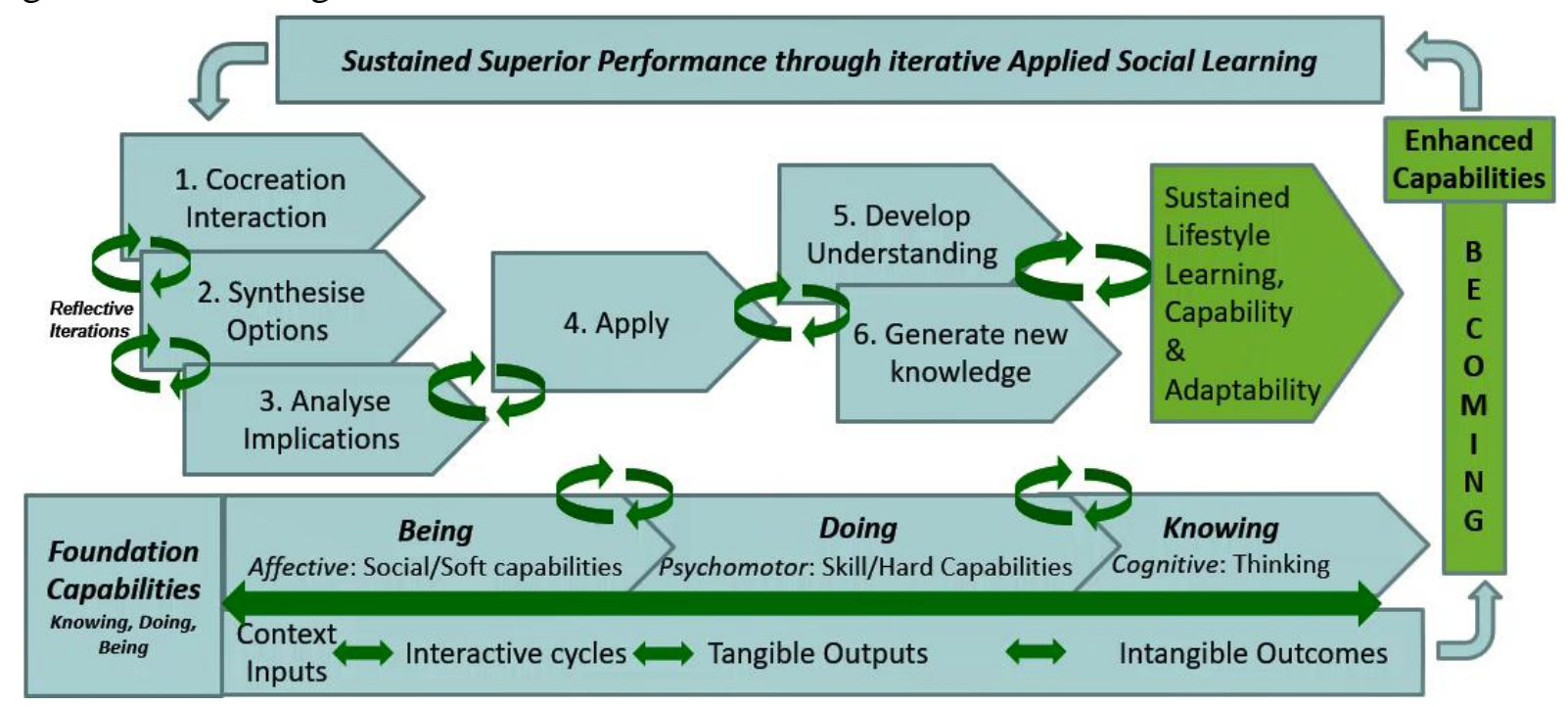

Figure 1 Reverse Bloom Learning Framework

Note: Cyclic arrows represent iterations of reflection to deepen learning within activities.

The RBLF incorporates all three Bloom domains and proposes a reversal of the "order" of the cognitive domain. That is, from co-creation "down" to knowledge, rather than the traditional approach from knowledge up to creation. This new approach applies the cognitive domain elements through experiences in iterative social learning cycles. What this means is (with a small exposure to some insights first), learners explore possibilities and implications of a real context through co-creative interactivities. This enables all people involved to synthesise and analyse implications as they deconstruct the challenge presented (RBLF actions 1-3). Once learners design or prototype some options, they apply them (RBLF action 4) to understand the best possibilities for further use. Reflections between the learners before, during and after each action stimulates socialization of the possibilities, which further expands their understanding (RBLF action/outcome 5). This deeper and wider understanding leads to the 
generation of new knowledge (RBLF action/outcome 6) and triggering professional processes like creativity and innovation.

In the RBLF approach, much of the knowledge generated is new, rather than just a transfer of prior existing knowledge, as each person can perceive the concept in a different way. This highlights why reflective conversations about their perspectives and understanding are important throughout the whole process. It enables all learners to benefit, from the understanding of everyone involved, not just from their own insights. They could possibly learn from reflections of prior learners as well, if artefacts for those experiences have also been kept. These reflective conversations happen throughout all cycles in the process to generate not just an understanding of the original concept, but a greater set of insights and new possibilities for adaption of the concepts into other options or fields. This cyclic, reflective, and social learning in real context is aligned with the Expansive Education (EE) approach discussed by Engeström \& Sannino (2016). EE cycles involve a range of iterative activities taking context and culture into account, to generate social change. The flow of EE activities are; questioning, analysis, modelling new options, evaluating these, implementing options in practice and finally reflecting on outcomes to embed insights into new practice.

\section{Design of learning activities and assessments for RBLF approach}

The RBLF is designed to be flexible, so that the principles of this learning approach can be applied to any level of learner (young children through to executives). The significant factor for design consideration of both activities and assessments is what level of capability does the learners already have and what new or elevated capabilities are to be developed. These steps are aligned with standard approaches to intervention and assessment design (Gershon, 2018; Biggs \& Tang, 2011), although with more emphasis on socialization and collaboration, and monitoring application of learning during the learning experience. This also highlights the benefits of support for ongoing development of capabilities beyond the formal learning experiences into professional practice, something outside the scope of most formal learning.

The generic steps to design a learning intervention and assessment are:

1. Assess the foundational capabilities (Knowledge, Skills and Social/Behavioral) of the learners to determine current and desired states and define the gap.

2. Consider the context of the learning and a real challenge to be resolved within this by the learners.

3. Define learning objectives across all three domains (Cognitive, Psychomotor and Affective) based on the learning outcomes to fill the capabilities gap.

4. Create a series of learning activities that are inclusive social experiences in which learners explore possibilities relevant to the challenge context.

5. Construct an assessment rubric that clarifies the changes to be demonstrated through the learning. Note this is likely to include some subjective measures of the quality of the capabilities. This is inevitable in social systems and happens all the time in workplaces. The rubric should be as explicit as possible to guide the learners, but not so rigid to disallow unpredicted creative solution the facilitator has not considered. Remembering that the RBLF acknowledges the value of co-creating new possibilities in addition to existing knowledge, within the context. 
6. Facilitate learning interventions that provoke divergent thinking and social exchanges around possibilities and prioritise actions.

7. Assess outputs and outcomes against the defined learning criteria

8. Provide meaningful and balanced individualised feedback. Feedback is optimal when it highlights the aspects that have been done well (demonstrated capabilities against planned learning outcomes defined in the rubric) and the aspects that they could have done better (learning gaps not met as defined by the rubric). If the planned learning is ongoing, as is usually the case in formal learning, the learner proceeds to the next learning activity. That is, back to step 1 for the new set of learning outcomes and activities.

9. Facilitate a reflective conversation with the learner is sometimes appropriate where the feedback is not understood or needs to be clarified.

Extend the learning into professional practice. Ongoing assessment (beyond the planned learning program - after "graduation") helps to reinforce, amplify and extend sustained learning. Follow up conversations with the learners after the formal parts of the learning has been "completed" enables them to consciously reflect on their progress. Assessing the impacts generated when capabilities are put into professional practice is helpful to refine capabilities. This encourages ongoing use of the learned capabilities to continue their development. This is where optimal return on investment comes for learning. When this is not done capabilities may not be put into practice and capabilities reduce over time, along with the potential value. Programs such as coaching and mentoring can assist with the motivation to ensure optimal return is achieved from the learning investment for all parties.

\section{A starter on RBLF principles}

Principles of learning for this framework are not significantly different from those in the general learning literature. However, more emphasis is applied to social interactions and iterative action learning. No doubt, as others experiment with the RBLF, more principles will emerge. The list below is not meant to be comprehensive, but offers a useful set of principles to begin designing and implementing your RBLF interactions:

- Engage to open minds rather than fill them, emphasise context over content.

- Aim to co-create a range of options rather than finding an existing answer.

- Embed iterative collaborative cycles of divergent and convergent thinking, laced with social challenges to explore the emotional and human aspects of the topics.

- Reinforce that creativity is a critical part of learning, as are sense making and play.

- Stimulate Creative Friction (constructive challenges to deliberately clash alternatives to co-create new possibilities) as a key driver.

- Proactively facilitate learner-centered experiences, with balanced cognitive, affective and psychomotor aspects.

- Optimal learning builds the capabilities and confidence of the learner to safely enter the unknown and explore (expanding their comfort zone).

- Social connections and trusted relationships should be outcomes of the learning 
- Invest heavily in reflective conversations through collaborative cycles to share perspectives.

- Invest in designs and facilitation that are inclusive of all perspectives.

- Aim to develop well-rounded people who feel competent to generate value from applying collaborative learning to continue to refine their capabilities ongoing.

Share insights and learnings from use of the RBLF with other practitioners to amplify what we can collectively achieve to further mature the approach.

\section{Discussion}

Some elements of holistic approaches and progressive learning have been embedded into a range of experiential learning approaches including, Student-centered Learning, Problembased Learning and Project-based Learning. Benefits from these alternative approaches have been described by educators exploring which elements generate high quality learning outcomes (Miller et. al., 2018). There is alignment between some aspects of these approaches and methods used in some successful non-mainstream educational institutions, such as Steiner Education (Edmunds, 2004) and the Association Montessori Internationale (AMI, 2020a). Montessori (2014) was an educational leader ahead of her time advocating for social, creative and holistic educational experiences to prepare students to enable them to become transforming agents in society leading to a more harmonious and peaceful world (AMI, 2020b). Some of the ideas have been incorporated into creative experiential activities in commercial professional development, for example Serious Play (Schulz et, al., 2015) and Experiential Workshops (MTA, 2020).

Historically, there has not been a single learning framework that combines the key insights of these concepts into an interconnected flow that is easily incorporated into mainstream education at all levels. The Reverse Bloom Learning Framework offers an opportunity to achieve this in one inclusive framework. The RBLF offers an adaptable approach for learning that incorporates the three Bloom domains into a series of iterative and interdependent learning experiences. It combines the collective perspectives of the learners as they explore possibilities around real challenges. This collaborative and social interaction stimulates cocreation of a range of potential options. It also leads to deeper understanding and the generation of new knowledge (effectively the exact reverse of the order of activities in the traditional use of Bloom's learning hierarchy). The suggested order of reversal applies to the modified (actionionable outcomes based) version as shown in Figure 2 (Shelley, 2017). Traditionally Bloms Hierarchy is taught from bottom up; Remember (knowledge) up to Create (or Co-create in this version). The reverse Bloom recommends top down; Co-Create, Evaluate, Analyse, Apply, Understand to Generate new knowledge (a shift away from just remember, or existing knowledge, in earlier versions). 


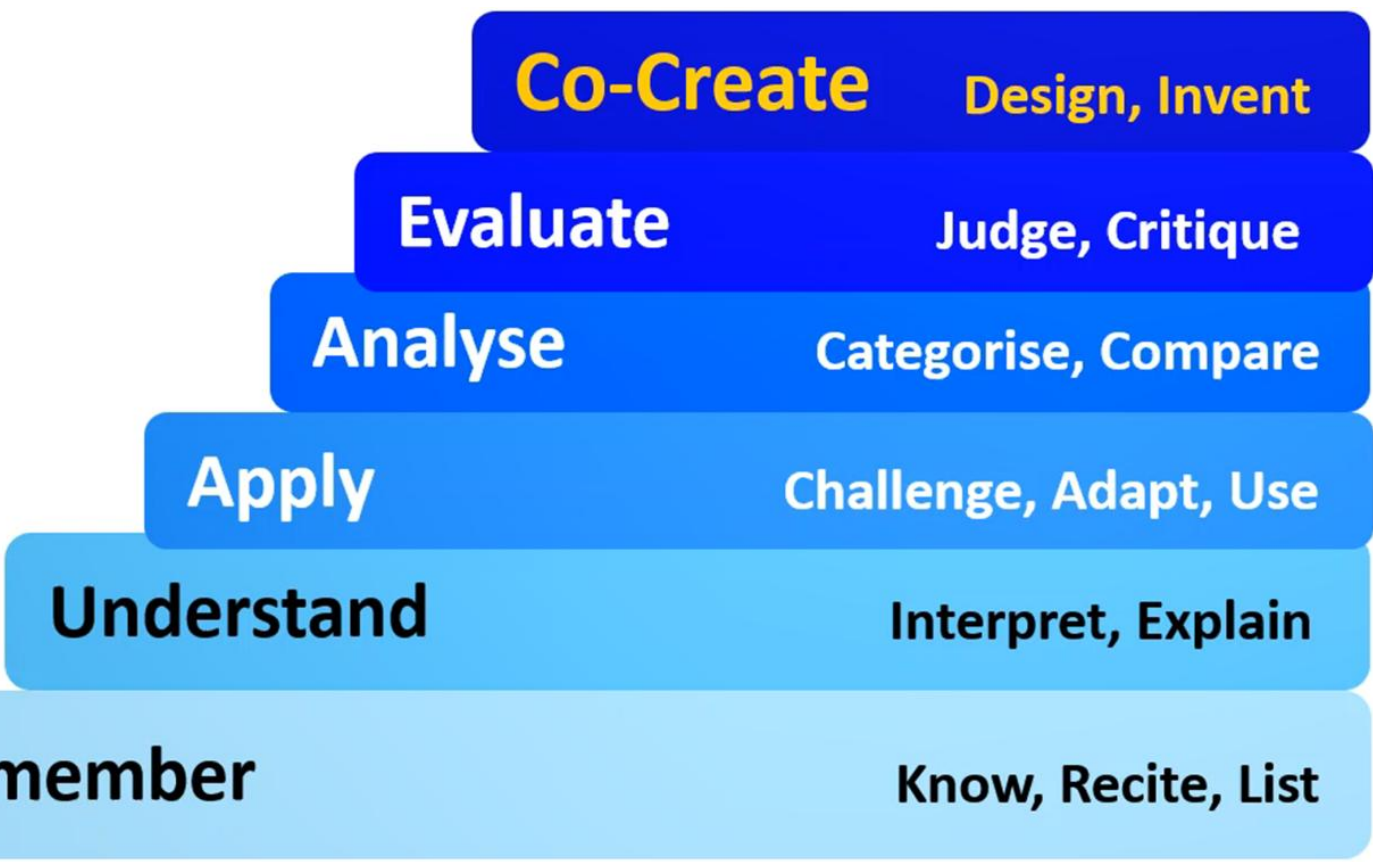

\section{Remember}

Know, Recite, List

Figure 2 Adapted verb-based version of Blooms Hierarchy of Learning (Shelley, 2017)

The name Reverse Bloom Learning Framework (RBLF) was chosen to respect the many existing models that leverage this concept and demonstrate this is an adaptation of how, rather than a rejection of what. However, it also highlights that it reverses the traditional order in the way the learning is done. RBLF involves actively engaging participants in learning interventions without prior coverage of the content (although a flipped classroom approach can complement this to further accelerate the learning by exposure to some content if desired). Although many of the concepts embedded into the RBLF already existed, this approach simplifies a process for learning facilitators of all leaves of experience to implement complex learning, in what appears to be a simple engaging environment. Learners perform better when they are actively involved in the learning process and are more motivated when it is inclusive and enjoyable (Shelley, Ooi, \& Brown, 2019). COVID-19 has generated a time of reflection around how we educate and why (Butler-Henderson, et al., 2020; Crawford et al., 2020).

This is a timely constructive challenge of what works best for our learners. There is emerging support for more socially constructed learning experiences based on collective knowledge and intelligence (Kolb \& Kolb, 2017; Shelley \& Goodwin, 2018; Kefalaki \& Diamantidaki, 2020), especially to consider improvements in remote learning (Downes, 2018) and mobile learning (Lim, Shelley, \& Heo, 2019). By including these aspects into the learning experience, the RBLF approach reconnects all three domains of Bloom's original approach (Cognitive, Psychomotor and Affective), providing a more holistic learning experience (Biggs, Harris, \& Rudolph, 2019).

If you look closely enough you can see some of the principles and elements of RBLF in some processes developed independently of learning theory. Practices like Design Thinking (Brown, 2009) and Agile Project Management (Morris \& Ma, 2014) are based on iterative 
cycles of divergent and convergent interactions. This is because people developing and facilitating such processes know that it works in practice. They do it because it achieves the outcomes they desire and are often unaware that it is aligned with learning principles. This simply reflects a natural style of problem-solving they have learned through practice, despite them not consciously considering learning theory literature. The RBLF provides such practitioners with a simple approach to achieve these outcomes with a little methodology embedded to achieve more consistent outcomes as it provides them with a more solid foundation and a generic process to follow. We do not seek to make learning practitioners out of professionals from other fields. However, embedding learning principles into all fields of pursuit is increasingly important in an ever-changing world.

Throughout the history of learning research and practice many examples of experiential and or social learning models, have been built around iterative cycles of investigation and inclusion of a range of perspectives. Some of the methods described that include aspects of this approach include; action learning (Revans, 1980), student-centered learning, (Wright, 2011), problem-based learning (Bethell \& Morgan 2011), and social learning (Van Epp, \& Garside, 2014). More widely the principles have been involved in the corporate professional development area (Keys, 1994; Schaefer, Vanderbilt, Cason, \& Navedo, 2011), and in design of engaging games (Kolb, \& Kolb, 2009).

Creating a social environment in which learners engage around challenges by taking deliberately different perspectives is a practice gaining wider application (Baker, Jensen, \& Kolb, 2002; Shelley \& Goodwin, 2018; Alvarez-Alvarez, Sanchez-Ruiz, Ruthven, \& Montoua Del Corte, 2019). Kolb and Kolb (2017, p 36) stated "Good conversation is more likely to occur in spaces that integrate thinking and feeling, talking and listening, leadership and solidarity, recognition of individuality and relatedness, and discursive and recursive processes." Recognising the right type of conversation for the learning moment is critical. There are times for the divergent exploratory conversation (leveraging creativity and brainstorming to create options) and a time for the convergent conversations (leveraging critical thinking, problem solving capabilities and prioritising options into a reduced list and form recommendations).

Since the development of the internet and digital learning opportunities, new learning preferences have emerged, especially around virtual and digital social contexts (Sousa-Vieira, et. al., 2016). These authors suggested that traditional education systems would benefit from evolving their practices to leverage these new approaches. Social Learning Strategies can be effective, although they are dependent on knowing who the best people are in the network to learn from (Heyes, 2016). Engaging learners in a social community is learning approach that can nurture learning and help address challenges faced in higher education (Culver and Bertram, 2017). Social engagement is harder to achieve in virtual environments, as the online environment is not as conducive to interactive conversations as face to face. Ironically, comfort levels with remote interactions have been increased by the COVID-19 pandemic (Bonk, et al., 2020), as people have been forced to become more familiar with on-line interactions in the forced remote workplace and education situations. Technology has 
improved dramatically as well, since technology providers actively compete for a bigger share of this suddenly accelerated demand. This has generated a wave of development, increased capabilities of both learning facilitators and learners that make remote learning a better experience for all involved.

\section{Some examples of activities that embed RBLF principles in virtual learning}

Technology is developing fast for virtual learning that goes beyond teaching content, especially in the area of play as a means of collaborative learning (Essmiller, 2020). The two examples described here are activities that have been creatively adapted to interactive online versions. Although designed and tested for face-to-face education before the COVID19 pandemic, these activities have been adapted to virtual interactions. The post-COVID-19 world will inevitably involve much more online learning (hopefully interactive and not just reading content), so adapting social learning interactions remains a priority.

\section{Virtual Escape Room}

Escape rooms have become a popular entertainment activity in recent years. Instead of a physical experience, the concept has been adapted to provide virtual learning by using breakout groups in on-line tools. Student groups move across a series of breakout rooms and need to solve some problems before they can be moved to the next "room". The problems to be solved involve demonstrating knowledge related to the stated learning outcomes. Visual clues and other creative or cryptic questions can be created to stimulate social interaction between members of the group.

The concept can be used as a starter in each lesson to highlight what learners can solve quickly and what they struggle with, thereby highlighting what topics need more attention. An advancement is gamification of the experience by keeping a "team scorecard" as they learners progress through series of sessions. Care should be taken to ensure that gamification motivates participants in a constructive way and does not become over competitive. Collaboration skills are important to social success, so reinforcing competition exclusively at the expense of collaboration is not a desirable approach. The development of collaboration games is starting to gain acceptance outside of learning and this makes a good trend to encourage further learning. Ways of implementing virtual escape room are only limited by the reach of your imagination.

\section{Co-created Projects Worth DOING (CPWD)}

CPWD is a process designed to generate ideas from all participants in a specified "action format" and then clustering these into projects for implementation (Shelley, 2019). The process has been used in executive education workshops to generate real project options for participants, which have generated social benefits. Some examples of the initiatives coming from such workshops are; a Chinese leadership delegation developed initiatives for pollution mitigation, a Vietnamese delegation created several projects to address the needs of a minority ethnic group, and an Australian based charitable organization were assisted to accelerate innovation in a workplace for people with disabilities. This process structures context-based actions into phrases starting with a verb to precisely define the next steps for success, a process aligned with attention to verbs in the SOLO Learning Taxonomy (Biggs, Harris, \& Rudolph, 2019). 
The Reverse Bloom Learning Framework and the shared activities in this paper have emerged through creative practices that have been informed by the rich history of educational literature outlined above. It is informed by the experimental approach to project-based learning in real contexts and reflective practice on shared experiences (Shelley \& Goodwin, 2018). In addition, insights have been taken from evolving novel approaches to learning (Ferguson et al., 2017). This framework when used in association with the principles outlined and inclusive interventions like those listed in this article, creates positive learning experiences (Shelley \& Goodwin, 2018).

\section{Conclusions}

The Reverse Bloom Learning Framework introduced in this article is an adaptation that combines a number of learning principles and models. Combined with the learning principles, design insights and examples shared in this article, the RBLF can be a powerful learning experience developing capabilities across all three learning domains. Although the RBLF is novel, it leverages strong interdisciplinary literature and evolving concepts across the history of education and learning practices. The RBLF simply connect these existing concepts to extend experiential approaches into an easily understood framework that enables facilitation of collaborative and social learning experiences. Facilitating learning interactions through the reverse direction, compared to traditional education approaches, generates a more comprehensive learning experience across the three key aspects (domains) of quality learning; knowing (cognitive), Doing (psychomotor) and Being (affective). The approach is flexible to enable learners of all capability levels to engage in (based on an assessment of their prior knowledge and experiences). This makes it accessible for educational practitioners to adopt and adapt to a wide range of learners by designing learning activities that align the principles of the approach with the desired learning outcomes. Reversing the mindset to experience co-creative interactions, before formalising deeper exploration of the content, provides a strong foundation for living, and creating options for challenges, in our modern virtual and VUCA (Volatile, Uncertain, Complex and Ambiguous) world.

The example techniques and concepts shared here are just the beginning of what is possible with the RBLF. Practitioners are encouraged to experiment with the concepts and share their experiences to further evolve our collective understanding. Collaborating on further development of this approach can engage learners to remain involved in ongoing learning experiences, because they love it and see value in lifestyle learning (Shelley and Goodwin, 2018). 


\section{References}

Alvarez-Alvarez, C., Sanchez-Ruiz, L., Ruthven, A., \& Montoua Del Corte, J. (2019). Innovating in University Teaching Through Classroom Interaction. Journal of Education, Innovation, and Communication, 1(1), 8-18.

Anderson, L. W., \& Krathwohl, D. R. (Eds.). (2001). Taxonomy for Learning, Teaching, and Assessing: A Revision of Bloom's Taxonomy of Educational Objectives (Abridged). New York, NY: Addison Wesley Longman, Inc.

AMI Association Montessori Internationale. (2020a). About AMI https://montessoriami.org/about-montessori

AMI Association Montessori Internationale. (2020b). AMI Vision and Mission https://montessori-ami.org/about-ami/our-mission

Baker, A. C., Jensen, P. J., \& Kolb, D.A., (2002). Conversational Learning: An Experiential Approach to Knowledge Creation. Westport, CT: Quorum Books.

Bethell, S. \& Morgan, K. (2011). Problem-based and Experiential Learning: Engaging Students in an Undergraduate Physical Education Module. Journal of Hospitality, Leisure, Sport and Tourism Education, 10(1), 128-34.

Biggs, J. B. \& Tang, C. (2011) Teaching for Quality Learning at University, Buckingham: Open University Press/McGraw Hill.

Biggs, J., Harris, C. W., \& Rudolph, J. (2019). Teaching for quality learning at changing universities. A tour de force of modern education history - an interview with Professor John Biggs. Journal of Applied Learning and Teaching, 2(1), 54-62.

Bloom, B. S., Englehart, M. D., Furst, E. J., Hill, W. H., \& Krathwohl, D. R. (1956). The Taxonomy of Educational Objectives, The Classification of Educational Goals, Handbook 1: Cognitive Domain. New York: David McKay Company Inc.

Bloom, B. S., Hastings, J. T., \& Madaus, G. F. (1971). Handbook on Formative and Summative Evaluation of Student Learning. New York, NY, USA: McGraw-Hill Book Company.

Bonk, R. J., Kefalaki, M., Rudolph, J., Diamantidaki, F., Munro, C. R., Karanicolas, S., et al. (2020). Pedagogy in the Time of Pandemic: From Localisation to Glocalisation Journal of Education, Innovation, and Communication, Special Issue, June 2020, 17-64.

Brown, T. (2009). Change by Design: How Design Thinking Transforms Organizations and Inspires Innovation. New York, NY: HarperBusiness.

Burton, R., \& Hope, A. (2018). Simulation based education and expansive learning in health professional education: A discussion. Journal of Applied Learning and Teaching, 1(1), 25-34.

Butler-Henderson, K., Crawford, J., Rudolph, J., Lalani, K., \& Sabu, K. M. (2020). COVID19 in Higher Education Literature Database (CHELD V1): An open access systematic literature review database with coding rules. Journal of Applied Learning and Teaching, 3(3), DOI: https://doi.org/10.37074/jalt.2020.3.2.11.

Chamane, N., \& Mashamba-Thompson, T. P. (2019). Experiential Learning Curriculum Delivery Approach for Quality Improvement in Resource Limited Settings: Mobile Learning for Point-of-Care Technologies Global Journal of Health Science, 11(13), 158-166. 
Crawford, J., Butler-Henderson, K. Rudolph, J., Malkawi, B., Glowatz, M., Burton, R., Magni, P., \& Lam, S. (2020). COVID-19: 20 countries' higher education intra-period digital pedagogy responses. Journal of Applied Learning \& Teaching, 3(1) 9-28.

Culver, D. M., \& Bertram, R. (2017). Learning Value and Identity Formation: Social Learning and the Graduate Studies Experience. In J. McDonald \& A. Cater-Steel (Eds.), Implementing Communities of Practice in Higher Education. Singapore: Springer.

Dewey, J. (1938). Experience \& Education. New York: Kappa Delta Pi.

Downes, S. (2018). Modernised learning delivery strategies: The Canada School of Public Service technology integration project. Journal of Applied Learning \& Teaching, 1(2), $15-25$.

Edmunds, F. (2004). An Introduction to Steiner Education: The Waldorf School. Forest Row: Sophia Books

Engeström, Y., \& Sannino, A. (2016). Expansive learning on the move: insights from ongoing research / El aprendizaje expansivo en movimiento: aportaciones de la investigación en curso. Infancia y Aprendizaje, 39(3), 401-435.

Essmiller, K. (2020). Learning Through Play. In B. Hokanson, G. Clinton, A. Tawfik, A. Grincewicz \& M. Schmidt (Eds.), Educational Technology Beyond Content. Educational Communications and Technology: Issues and Innovations. Springer International Publishing.

Freeth, R., Caniglia, G. (2020). Learning to collaborate while collaborating: advancing interdisciplinary sustainability research. Sustainability Science 15, 247-261.

Ferguson, R., Barzilai, S., Ben-Zvi, D., Chinn, C. A., Herodotou, C., Hod, Y., . . . Whitelock, D. (2017). Innovating Pedagogy 2017: Open University Innovation Report 6. Milton Keynes: The Open University, UK.

Gershon, M. (2018). How to use Bloom's Taxonomy in the Classroom: The Complete Guide. West Palm Beach, FL: Learning Sciences International.

Hayden, M., \& McIntosh, S. (2018). International education: the transformative potential of experiential learning. Oxford Review of Education 44(4), 403-413.

Heyes, C. (2016). Who Knows? Metacognitive Social Learning Strategies. Trends in Cognitive Sciences, 20(3), 204-213.

Kefalaki, M. K., \& Diamantidaki, F. (2020). Nurturing Collective Knowledge and Intelligence: Social phenomena and implications for practice. Journal of Education, Innovation, and Communication, 2(1), 7-9.

Keys, L. (1994). Action Learning: Executive Development of Choice for the 1990s. Journal of Management Development, 13(8), 50-56.

Kolb, A. Y., \& Kolb, D. A. (2017). Experiential Learning Theory as a Guide for Experiential Educators in Higher Education. Experiential Learning \& Teaching in Higher Education, 1(1 Article 7), 7-44.

Kolb, A., \& Kolb, D. (2009). The learning way: Meta-cognitive aspects of experiential learning. Simulation \& Gaming, 40, 297-327.

Lim, G., Shelley, A. W., \& Heo, D. (2019). The regulation of learning and co-creation of new knowledge in mobile learning. Knowledge Management \& E-Learning, 11(4), 449-484. 
Miller, R. (1997). What Are Schools For? Holistic Education in American Culture, 3rd Edition. Brandon, VT: Holistic Education Press.

Miller, J.P. Nigh, K., Crowell, S., Novak, B., Binder, M. J. (2018). International Handbook of Holistic Education. New Your, NY: Routledge.

Montessori, M. (2014). The Montessori Method. New Brunswick, NJ. Transaction Publishers. Morris, L., \& Ma, M. (2014). Agile Innovation: The Revolutionary Approach to Accelerate Success, Inspire Engagement, and Ignite Creativity. Hoboken, NJ: John Wiley and Sons.

MTA (2020) Experiential Learning Knowledgebase. Retrieved from https://www.experientiallearning.org/knowledge-centre/

NJMED New Jersey Minority Educational Development (2018). World's Top Education Systems. Retrieved from https://worldtop20.org/worldbesteducationsystem.

Novartis (2018) Vas Narasimhan and author Dan Pink talk culture and leadership. Retrieved from https://youtu.be/PGz2MJKIkIk

Novartis (2019) Talking culture transformation with Vas Narasimhan and Adam Grant. Retrieved from https://youtu.be/hGwSvD7thgY

OECD (2018). Education at a glance. Retrieved from http://www.oecd.org/education/education-at-a-glance/

Revans, R.W. (1980). Action Learning: New Techniques for Management.

London: Blond \& Briggs.

Robinson, K., \& Aronica, L. (2016) Creative Schools. Penguin Books.

Schaefer, J. J., Vanderbilt, A., Cason, C.L. \& Navedo, D., (2011). Literature Review: Instructional Design and Pedagogy Science in Healthcare Simulation. Simulation in Healthcare, 6(7), S30-S41.

Schenck, J., \& Cruickshank, J. (2015). Evolving Kolb: Experiential Education in the Age of Neuroscience. Journal of Experiential Education, 38(1), 73-95.

Shelley, A. W. (2014). Active learning innovations in knowledge management education generate higher quality learning outcomes Journal of Entrepreneurship Management and Innovation, 10(1), 129-145.

Shelley, A. W. (2017). KNOWledge SUCCESSion. Sustained performance and capability growth through strategic knowledge projects. New York, NY: Business Expert Press.

Shelley, A. W. (2020). Cocreated Projects Worth Doing. Journal Technology and Governance, 1(1).

Shelley, A. W., \& Goodwin, D. (2018). Optimising learning outcomes through social cocreation of new knowledge in real-life client challenges. Journal of Applied Learning \& Teaching, 1(2), 26-37.

Shelley, B., Ooi, C. S., \& Brown, N. (2019). Playful learning? An extreme comparison of the Children's University in Malaysia and in Australia. Journal of Applied Learning \& Teaching, 2(1), 16-23.

Slavich, G. M., \& Zimbardo, P. G. (2012). Transformational Teaching: Theoretical Underpinnings, Basic Principles, and Core Methods. Educational Psychology Review, 24(4), 569-608.

Smuts, J.C. (1926). Holism and Evolution. London: Macmillan \& Co. 
Sousa-Vieira, M. E., López-Ardao, J. C., Fernández-Veiga, M., Rodríguez-Pérez, M., \& Herrería-Alonso, S. (2016). An open source platform for using gamification and social learning methodologies in engineering education: Design and experience. Computer Applications in Engineering Education, 24, 813-826.

Schulz, K.-P., Geithner, S., Woelfel, C., \& Krzywinski, J. (2015). Toolkit-Based Modelling and Serious Play as Means to Foster Creativity in Innovation Processes. Creativity and Innovation Management, 24(2), 323-340.

Van Epp, M., \& Garside, B. (2014). Monitoring and Evaluating Social Learning: A Framework for Cross-Initiative Application. CCAFS Working Paper no. 98. Copenhagen, Denmark: CGIAR Research Program on Climate Change, Agriculture and Food Security (CCAFS).

Victorian Department of Education and Training (2020). The Victorian Curriculum F-10. Retrieved from https://victoriancurriculum.vcaa.vic.edu.au/

WEF (2020a). World Economic Forum. Future of Jobs Report. Retrieved from http://www3.weforum.org/docs/WEF_Future_of_Jobs_2020.pdf

WEF (2020b). World Economic Forum. Human Capital as an Asset: An Accounting Framework to Reset the Value of Talent in the New World of Work. Retrieved from https://www.weforum.org/reports/human-capital-as-an-asset-anaccounting-framework-to-reset-the-value-of-talent-in-the-new-world-of-work

Wright, G. B., (2011). Student-Centered Learning in Higher Education. International Journal of Teaching and Learning in Higher Education, 23(3), 92-97.

Yardley, S., Teunissen, P. W., \& Dornan, T. (2012). Experiential learning: transforming theory into practice. Medical Teacher, 34(2), 161-164.

Zilliacus, H., Holm, G., \& Sahlström, F. (2017). Taking steps towards institutionalising multicultural education - The national curriculum of Finland. Multicultural Education Review, 9(4), 231-248. 


\section{Equipping Parents for Effective HOME Schooling}

Journal of Education, Innovation and

Communication (JEICOM)

46-55

Vol. 2. Issue 2, December 2020

DOI: 10.34097/jeicom-2-2-Dec2020-3

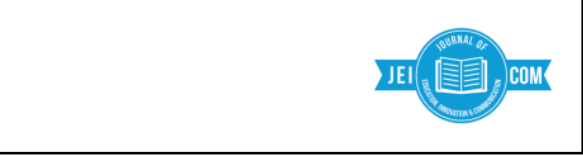

Philip Pohlman ${ }^{7}$

Erin Herbst ${ }^{8}$

\begin{abstract}
The COVID-19 crisis has shuttered schools across the globe and left millions of schoolchildren quarantined. This pandemic has highlighted the importance of adequately educating homebound children. Although homeschooling has been growing in popularity in some areas of the world, particularly in the United States, it has not constituted a large percentage of the educational establishment in any part of the world. There has been debate about homeschooling for decades. This paper aims to show that success with homeschooling is possible and it will provide suggestions for empowering families to achieve that.

Four ways to empower home educators have been summarized into the HOME acronym. This acronym stands for $(\mathrm{H})$ helping families find their fit, $(\mathrm{O})$ offering a diversity of teaching resources, $(\mathrm{M})$ making homeschooling socially acceptable, and (E) empowering homeschool partnerships. These practices can serve as a template for organizations that wish to support families who choose to homeschool their children or who are forced to by global constraints.

The recent crisis has provided an opportunity for nations, organizations, families, and students to share the leadership of their educational resources and practices. Collaboration and cooperation can help ensure homebound children receive the education they need. This type of collaboration will help prepare the world for the educational challenges the future might bring.
\end{abstract}

Keywords: Homeschool, Homeschooling, Education, Coronavirus, and COVID-19.

\footnotetext{
${ }^{5}$ John Kinzer, MA, Director, Rio Grand Enrichment Studies LLC, USA. Email: jdkinzer@msn.com

${ }^{6}$ Nathaniel Herbst, PhD, Team Coordinator, Great Commission Alliance, USA. Email: nate@ gcateam.org

${ }^{7}$ Philip Pohlman, MPD Coach, Lighthouse Charitable Foundation, USA. Email: philipapohlman@ hotmail.com

${ }^{8}$ Erin Herbst, MA, Homeschool Educator, USA. Email: ejoyherbst@yahoo.com
} 


\section{Introduction}

Many countries have closed their schools in response to the COVID-19 crisis and most of the globe's schoolchildren have been impacted (UNESCO, 2020). Homeschooling, which up until now has been on the fringes of the educational spectrum, has become a practice of global importance. Success with homeschooling is possible and support for homeschoolers can help achieve that.

Before going any further, a disclosure must be made. Three of this article's authors were homeschooled as children, three have homeschooled their own children, and one is the founder and director of the Rio Grande Enrichment Studies LLC (RGES) homeschool service. These authors could hardly be deemed un-biased. Still, two have completed degrees in education, giving them an understanding of issues related to both home and public schooling. The authors also share nearly six decades of combined experience in homeschooling.

The current paper is not intended to provide an exhaustive analysis of homeschooling. Rather, it will summarize some of the research that shows homeschooling success is possible. Much of the research that will be considered is based on homeschooling in the United States but some other countries' experiences will be considered as well. Finally, based on the literature, the paper will propose the HOME acronym, advocating $(\mathrm{H})$ helping families find their fit, (O) offering a diversity of teaching resources, (M) making homeschooling socially acceptable, and (E) empowering homeschool partnerships. These are a few ways to practically support homeschooling families.

\section{Homeschooling can be a viable model}

Homeschooling is not a new phenomenon in the United States. Gordon and Gordon (1990) explain, "During the colonial experience we know that a broad formal education was given in many households by a tutor or parent" (p. 266). The traditional one-room schoolhouse, famous in New England in early America for teaching students of various ages and grades, achieved a very high literacy rate. John Adams remarked in 1765 that, "all ranks and orders of our people are intelligent, are accomplished - a native of America, especially of New England, who cannot read and write is as rare a phenomenon as a comet" (Smith, 1966, p. 395). From a study of materials from 1640-1700, Samuel E. Morison found a $95 \%$ literacy rate in Massachusetts (Morison, 1960). Morison (1960) noted that the schools used the Bible as their central text and that families were heavily involved in teaching in the home and selecting the schoolmasters for these local schools.

Although parents were more involved in their children's education earlier in American History, the modern homeschool revolution is a relatively new phenomenon. Gaither (2009) explains, "the homeschooling movement in the USA emerged in the 1970s" and "the movement's goals of legalizing and popularizing homeschooling were realized by the mid1990s" (p. 331). Families across America are continuing to adopt this approach to education. Mazama and Lundy (2015) note that, "Homeschooling, and academic interest in this phenomenon, have increased tremendously over the last decade" (p. 123). Homeschooling comprised just $0.03 \%$ of the United States educational system in the 1970's but has grown 
113-fold to 3.4\% in the past forty years (Ray, 2017). Ray (2017) adds, "It appears that homeschooling is continuing to grow and will do so into the foreseeable future" (p. 617). This is true in general but it is also true among minority demographics, like in the African American community (Mazama \& Lundy, 2013; Mazama \& Lundy, 2015), and among families with children with disabilities and special needs (Cook, Bennett, Lane, \& Mataras, 2013).

The trend is also expanding beyond the United States. It is being utilized in many European countries (Blok \& Karsten, 2011) and in other areas, like Malaysia (Alias, Rahman, Siraj, S., \& Ibrahim, 2013), Australia, Canada, Japan, Kenya, Russia, Mexico, South Korea, Thailand, and more (Ray, 2015b). Although popular in America, homeschooling is also a growing educational alternative in many countries.

\section{Values of homeschooling}

There are many reasons families choose to homeschool. Tilhou (2020) notes that many families value "strong family bonds, teaching faith, closely guided social interaction, and responsive pedagogy" but doubt that public education can achieve these goals (p. 75). Another reason that motivates some families is the fact that homeschooling can empower parents to ensure that their children receive the education they deserve while mitigating inequitable outcomes they might otherwise encounter (Dennison, Lasser, Awtry Madres, \& Lerma, 2020).

In a study of 100 homeschooling families, Baidi (2019) found that homeschooling can enable parents to best meet the needs of their children and inspire children to learn in both academic and practical contexts. Although some have publicized potential negative homeschooling outcomes, like a lack of socialization, parents can intentionally address these issues to help their children thrive in these areas as well (Firmin, Younkin, Sackett, Fletcher, Jones, \& Parrish, 2019).

Religion can influence homeschooling choices also. In Malaysia, for example, religion is a key driving force in homeschooling (Alias et al., 2013). Religious conservatives also comprise a large percentage of American homeschoolers (Kunzman, 2010). Kunzman (2010) explains, "The relative freedom and flexibility of homeschooling allows parents to craft an educational environment that reflects their values and priorities, and religious conservatives find such an option particularly appealing" (p. 18). Many American Christian families feel a deep sense of responsibility for their children's education because of various biblical passages. One example of this is Proverbs 22:6 (New International Version), which states "Train a child in the way he should go, and when he is old he will not turn from it." The importance of training children in an understanding of the Bible and the Christian Worldview is a primary motivation for some Christian homeschool families.

Although religious conservatives make up a large part of the American homeschooling demographic, they are not the only ones homeschooling their children. World-renowned homeschool researcher Brian D. Ray notes that current homeschooling trends have seen participation from many different parts of the societal spectrum (Ray, 2015b). Some nonreligious families are also taking the educational process for their families into their own hands out of a desire for higher academic achievement, individualized instruction, stronger family-focused learning, or the passing on of family values (Ray, 2015b). Today, there are 
Christians and atheists, conservatives and liberals, and families with many different ethnic, educational, and financial backgrounds participating in homeschooling (Ray, 2015b). Homeschooling appeals to a large and diverse group of people for a plethora of motivations. Various teaching resources can help parents succeed in homeschooling. Technological advances and tools have made homeschooling more accessible to more people. Curriculum choices can also be beneficial. Allowing parents flexibility in how they teach can also be important. Each will be considered below.

The role of technology in homeschooling is growing. Walters (2015) found that various technological tools, like computers and smartphones, are helpful resources for homeschoolers. Various technological options, like the internet, social networking sites, mobile learning solutions, interactive video games, and others, have also shown value in the homeschooling arena (Alias et al., 2013). Andrade (2008) found that computer and communication technologies helped lower barriers to homeschooling and helped parents successfully continue homeschooling. Technological advancements are providing new tools for homeschoolers.

One of the values of the homeschooling approach is the ability to tailor curricula to a student's particular needs and learning style. Research has found that homeschooling parents "use a variety of teaching and learning strategies including individualized instruction, mastery learning, self-directed study, collaboration with peers and adults, and application and connection of information" (Gann \& Carpenter, 2018). Cardinale (2015) found similar attributes, including, "strong nuclear families, direct teaching, self-study or self-directed education, mastery learning, purposive conversations, and challenging curriculum" helped homeschooled children succeed (p. 3). Efford and Becker (2017) elaborate:

'Child-centered and child-driven learning can provoke the creation of curriculum that is responsive to students' particular learning needs, is engaging and meaningful, and promotes learner agency. Homeschool settings provide opportunities for parent/educators cognizant of child-centered and child-driven curriculum to meet students' interests, readiness, growth, and educational drive with responses tailored for each unique situation'. (p. 34)

Hirsh (2019) summarizes, "Homeschool families are hyper-autonomous units with tremendous freedom to create curriculum, redesign typical learning pathways, and build innovative partnerships" (p. 1).

For example, some minority households have chosen to homeschool their children in order to circumvent the institutions that have at times perpetuated inequalities (Dennison et al., 2020). Mazama and Lundy (2013) found that many "African American homeschoolers believe a Eurocentric curriculum is bound to gravely interfere with their children's self-esteem and sense of purpose" (p. 123). Others are frustrated with the poor quality of public and private education available to them (Mazama \& Lundy, 2015). African American homeschoolers have performed better than their publicly educated counterparts in reading, language, and mathematics (Ray, 2015a). Similarly, some Hispanic parents choose to homeschool so they can be more involved in their children's education and so their children will learn their parents' language and culture (Easterday, 2011). Helping families find their fit is one way to equip them for homeschooling success.

In a qualitative analysis of 15 homeschooling families, Firmin et al. (2019) found that parents were able to help their children achieve success in their education by adapting their 
educational approaches to their children's specific needs. They also found that these families reported greater levels of bonding between parents and children (Firmin et al., 2019). Pannone (2014) found that many different objectives can drive homeschooler curriculum selection, including recommendations, religious and moral beliefs, and a child's needs and desires, and that homeschooling curricula can adapt over time. Various aspects, like "collaboration, community, faith, individualized instruction, and structure," are common among homeschoolers (Thomas, 2015, p. v). Specializing curricula to meet children's needs is a common theme in homeschooling and offering a diversity of teaching resources can help home educators thrive.

The curriculum is not the only thing that matters in a child's education. One of the values of the homeschooling approach is the ability to foster a child's intrinsic motivation to learn, something that cannot always be achieved in a crowded public education system with limited time and rigid curricula (Riley, 2016). Homeschooling allows parents to adapt what they teach but it also enables them to adjust how they teach, helping them inspire their children to learn.

\section{Potential disadvantages associated with homeschooling}

Lubienski, Puckett, and Brewer (2013) insist there is a "remarkable lack of empirical evidence on the effectiveness of this popular approach" (p. 378). Although some might argue with their assertion, there are undeniable barriers to homeschooling. Some parents may feel inadequately prepared to meet the educational needs of their children. There can be a financial burden associated with homeschooling as well. Resources and curricula can be expensive. Homeschooling families often sacrifice potential incomes as well (Isenberg, 2007). The time requirements associated with homeschooling can be demanding, especially for single parents. These issues can also limit the career opportunities of homeschooling mothers (Isenberg, 2007). Giving each child the attention they need, can also be difficult.

In their survey of German children, parents, and educators who were forced into homeschooling due to the COVID-19 crisis, Letzel, Pozas, and Schneider (2020) found significant issues. Students reported less time in education, decreased attention for different ability levels, and general feelings of listlessness, boredom, and worry (Letzel, Pozas, \& Schneider, 2020). Parents noted a lack of teacher support and reported negative emotions including stress, anger, and nervousness (Letzel et al., 2020). Teachers also admitted various struggles (Letzel et al., 2020).

This paper cannot provide final answers to all of these issues but it will show that the model can work. Even though the current crisis has forced many into home-based education, families and students can still achieve educational success. Although there are persistent stigmas associated with homeschooling, making homeschooling socially acceptable can help empower families to circumvent these barriers and succeed with this approach.

\section{Benefits that have been associated with homeschooling}

There is research that affirms the value of homeschooling as well. Some of that will be considered here with an emphasis on work by noted homeschool researcher Brian D. Ray. He has compiled an extensive collection of evidence that demonstrates a generally positive 
relationship between homeschooling and academic achievement, social development, and success in adulthood (Ray, 2013; Ray, 2017).

In fact, in his survey of a wide range of research on the topic, Ray (2017) found that the vast majority of empirical studies showed that the results of homeschooling outperformed public schooling, a small percentage found similar results for the two, and only a few studies reported homeschooling results that were inferior to public schooling ones. Some of Ray's previous research has indicated that "homeschoolers scored 34-39 percentile points higher than the norm on standardized achievement tests" and that the "national average ranged from the 84th percentile for Language, Math, and Social Studies to the 89th percentile for Reading" (Ray, 2009, p. 3). Ray (2010) surveyed 11,739 students and found that across the standardized testing spectrum, overall homeschooler "scores are well above public school student averages" (p. 27-28). He added that this result was unsurprising and consistent with other research in this area (Ray, 2010).

Research has discovered positive outcomes in other domains as well. Ray (2018) has demonstrated that homeschoolers have lower incidence of abuse than their publicly schooled counterparts. Homeschool adolescents are less likely to approve of using, have access to, or abuse substances like alcohol or marijuana (Vaughn et al., 2015). White, Moore, and Squires (2009) evaluated 51 previously homeschooled college students using the Big Five personality model and found them to be equal to their publicly schooled counterparts in extraversion and neuroticism domains and significantly ahead of them in the agreeable, conscientious, and open domains. Another evaluation of homeschooled college students found they had lower levels of depression than their publicly schooled counterparts and viewed their college experience more positively as well (Drenovsky \& Cohen, 2012).

Ray (2010) notes that some variables, like parent education level, have been associated with homeschool student success but only weakly. Dickson, Gregg, and Robinson (2016) explain a general principle that parents with high levels of education often raise children with high levels of education. Parent education levels can benefit children but are not a prerequisite for effective homeschooling. Ray (2010) warns that other factors, like the amount of homeschool regulation by the state, have only minimal, if any impact on student achievement.

There are also advantages that go beyond the students and their families. The United States currently spends more than $\$ 12,000$ per full-time equivalent student ("Education Expenditures by Country," 2019). A recent survey by the National Center for Education Statistics found that around 1.69 million Americans are currently being homeschooled (McQuiggan, Megra, \& Grady, 2017). These numbers would indicate that homeschooling families save United States taxpayers more than 20 billion dollars annually.

\section{Supporting homeschooling families}

Providing support for homeschooling families can help mitigate hindrances and equip families for success. Resourcing home educators with virtual tools and online resources can be helpful. Giving tax credits or access to funding for educational needs can offset costs. States do not have to view homeschooling in a negative light and can collaborate with families to ensure children's needs are being met.

Many homeschool groups have arisen to supplement families' efforts in homeschooling. Thomas (2015) notes, "There have been more instances in recent years of mixed educational 
programs across the United States" (p. v). Hirsh (2019) identifies some of these as "online schools, microschools, co-ops, and support centers" (p. 1). These organizations exist primarily to help families "share resources, expertise, and common values" (Tilhou, 2020, p. 75). Hybrid homeschool organizations are one of these types of organizations that have been growing in popularity. Wearne (2019) defines a hybrid homeschool as "a school in which students attend school on a campus for (typically) two to three days per week, and work at home the rest of the week." Many families will opt for hybrid homeschools because of their desire for smaller class sizes, education that aligns with their religious convictions, schedule flexibility, and more opportunities for the family to spend time together (Wearne, 2019). Empowering homeschool partnerships has helped many families and it can be an important part of a successful approach to home education.

\section{Conclusion}

The COVID-19 pandemic has presented an opportunity for the world to open up to the possibilities of home education. Homeschooling presents a unique opportunity for parents to adapt and customize their children's education to match their specific learning styles and strengths. The goal of this article has been to provide guidance for families who have utilized this model of education in light of the pandemic. Within that context, an analysis of some of the literature on the topic of homeschooling has been considered. There are other perspectives on this topic and readers should apprise themselves of those. Homeschooling is a viable and effective means of educating children. How nations and organizations support homeschooling families can directly impact the quality of home education and maximize its efficacy.

Four ways a society can support homeschooling can be summarized with the HOME acronym. First, authorities can assist home educators by $(\mathrm{H})$ helping families find their fit. They can do this by supporting and encouraging families to customize their education techniques to match the individual needs of each child. Next, a society can support homeschooling families by $(\mathrm{O})$ offering a diversity of teaching resources. These can include technological and curriculum options. Third, nations can support education in the home by (M) making homeschooling socially acceptable. Through acknowledging and informing the public on the benefits of this practice, the false stigmas that often encumber homeschoolers will be mitigated. Last, by (E) empowering homeschool partnerships, a society can open up more doors for hybrid homeschool organizations and associations to form. This can lead to greater success in the homeschool community.

The risks that are present in today's dynamic world have highlighted the educational vulnerability of the global community. New approaches are needed to ensure children receive the support they need. By sharing educational leadership with families, nations can prepare them to effectively educate their children even in the context of dire global pandemics or other educational interruptions they might encounter. 


\section{References}

Alias, N., Rahman, M., N., A., Siraj, S., \& Ibrahim, R. (2013). A model of homeschooling based on technology in Malaysia. The Malaysian Online Journal of Educational Technology. 1 (3), 10-16.

Andrade, A., G. (2008). An exploratory study of the role of technology in the rise of homeschooling. (Doctoral Dissertation). Ohio Department of Higher Education Electronic Theses and Dissertations Center.

Baidi, B. (2019). The Role of Parents' Interests and Attitudes in Motivating Them to Homeschool Their Children. Journal of Social Studies Education Research. 10 (1):156177.

Blok, H., \& Karsten, H. (2011). Inspection of Home Education in European Countries. European Journal of Education. 46 (1). 138-152.

Cardinale, B., R. (2015). Secrets of Their Success: A Multiple Case Study of Mathematically Proficient Homeschool Graduates. (Doctoral Dissertation). Liberty University Digital Commons.

Child abuse of public school, private school, and homeschool students: evidence, philosophy, and reason. (2018, January 23). https://www.nheri.org/child-abuse-of-public-schoolprivate-school-and-homeschool-students- evidence-philosophy-and-reason.

Cook, K., B., Bennett, K., E., Lane, J., D., \& Mataras, T., K. (2013). Beyond the brick walls: Homeschooling students with special needs. Physical disabilities: Education and related services. 32 (2), 90-103.

Dennison, A., Lasser, J., Awtry Madres, D., \& Lerma, Y. (2020). Understanding families who choose to homeschool: Agency in context. School Psychology, 35 (1), 20-27.

Dickson, M., Gregg, P., \& Robinson, H. (2016). Early, late or never? When does parental education impact child outcomes? Economic journal, 126, F184-F231. https://doi.org/10.1111/ecoj.12356

Drenovsky, C., K., \& Cohen, I. (2012). The impact of homeschooling on the adjustment of college students. International Social Science Review. (87, 1/2). 19-34.

Education expenditures by country. (2019, May). https://nces.ed.gov/programs/coe/indicator_cmd.asp

Easterday, L. (2011). Cross-cultural educational fallbacks: A study of homeschooling in the Hispanic community and the reasons for its utilization. Symposium on Undergraduate Research and Creative Expression (SOURCE). 5.

Efford, K., E., \& Becker, K. (2017). Home-Schooled Students And Their Teachers: Provoking

Curriculum Together Through Child-Driven Learning. Journal of Unschooling and Alternative Learning, 11 (22), 34-52.

Firmin, M. W., Younkin, F. L., Sackett, T. A., Fletcher, J., Jones, T., \& Parrish, E. (2019). Qualitative Perspectives of Homeschool Parents Regarding Perceived Educational Success. Journal of Higher Education Theory \& Practice, 19 (1), 44-55.

Gaither, M. (2009). Homeschooling in the USA: Past, present and future. Theory and Research in Education, 7 (3), 331-346. 
Gann, C., \& Carpenter, D. (2018). STEM Teaching and Learning Strategies of High School Parents with Homeschool Students. Education and Urban Society, 50 (5), 461-482.

Gordon, E., E., \& Gordon, E., H. (1990). A history of alternative education in America and Western Europe. Lanham, Maryland: University Press of America.

Hirsh, A. (2019). The Changing Landscape of Homeschooling in the United States. Center on Reinventing Public Education, 1-8.

Isenberg, E., J. (2007). What Have We Learned About Homeschooling? Peabody Journal of Education. 82 (2-3), 387-409.

Kunzman, R. (2010). Homeschooling and religious fundamentalism. International Electronic Journal of Elementary Education. 3 (1), 17-26.

Letzel, V., Pozas, M., \& Schneider, C. (2020). Energetic Students, Stressed Parents, and Nervous Teachers: A Comprehensive Exploration of Inclusive Homeschooling During the COVID-19 Crisis. Open Education Studies, 2 (1), 159-170.

Lubienski, C., Puckett, T., \& Brewer, T. J. (2013). Does Homeschooling "Work"? A Critique of the Empirical Claims and Agenda of Advocacy Organizations. Peabody Journal of Education, 88 (3), 378-392.

Mazama, A., \& Lundy, G. (2013). African American Homeschooling and the Question of Curricular Cultural Relevance. Journal of Negro Education, 82 (2), 123-138.

Mazama, A., \& Lundy, G. (2015). African American Homeschooling and the Quest for a Quality Education. Education and Urban Society, 47 (2), 160-181.

McQuiggan, M., Megra, M., \& Grady, S. (2017). Parent and family involvement in education: Results from the National Household Education Surveys program of 2016: First look. Washington, DC: U.S. Department of Education.

Morison, S. (1960). The Intellectual Life of Colonial New England. Ithaca, NY: Cornell Univ. Press.

New International Version of the Bible. Grand Rapids, Michigan: Zondervan, 1984. Print.

Pannone, S., J. (2014). Homeschool Curriculum Choices: A Phenomenological Study. (Doctoral Dissertation). Liberty University Digital Commons. iL

Ray, B. D. (2009). Homeschool Progress Report 2009: Academic Achievement and Demographics. Home School Legal Defense Association. 1-8.

Ray, B. D. (2010). Academic achievement and demographic traits of homeschool students: a nationwide study. Academic Leadership Journal, 8 (1), 1-32.

Ray, B. D. (2013). Homeschooling associated with beneficial learner and societal outcomes but educators do not promote it. Peabody Journal of Education, 88 (3), 324-341.

Ray, B. D. (2015a). African American homeschool parents' motivations for homeschooling and their black children's academic achievement. Journal of School Choice, 9, 71-96.

Ray, B. D. (2015b). Research facts on homeschooling. National Home Education Research Institute, March 2015,

https://eric.ed.gov/?id=ED556234. Accessed 17 Oct 2020.

Ray, B. D. (2017). A Systematic Review of the Empirical Research on Selected Aspects of Homeschooling as a School Choice. Journal of School Choice, 11 (4), 604-621.

Riley, G. (2016). The role of self-determination theory and cognitive evaluation theory in home education. Cogent Education, 3 (1). 1-7. 
Smith, W. (1966). The Teacher in Puritan Culture, Harvard Educational Review, 36 (4). 394411.

Thomas, J., D. (2015). Toward a mixed home-public education: Understanding homeschool curriculum and instruction. (Doctoral Dissertation). Texas Tech University Libraries.

Tilhou, R. (2020). Contemporary Homeschool Models and the Values and Beliefs of Home Educator Associations: A Systematic Review. Journal of School Choice, 14 (1), 75-94.

UNESCO (2020). Education: From disruption to recovery. https://en.unesco.org/covid19/educationresponse

Vaughn, M., G., Salas-Wright, C., P., Kremer, K., P., Maynard, B., R., Roberts, G., \& Vaughn, S. (2015). Are homeschooled adolescents less likely to use alcohol, tobacco, and other drugs? Drug and Alcohol Dependence. 155. 97-104.

Walters, L., A. (2015). Relationships of parental homeschooling approaches including technology integration. (Doctoral Dissertation). https://aquila.usm.edu/dissertations/106.

Wearne, E. (2019). Parent and Administrator Perceptions of Hybrid Homeschools. Catholic Social Science Review, 24,

177-193.

White, S., Moore, M., and Squires, J. (2009). Examination of previously homeschooled college students with the Big Five model of personality. Home School Researcher. 25 (1). 


\title{
Evaluating Mandarin language students' online experience during Covid-19: \\ A case study from London
}

Journal of Education, Innovation and Communication (JEICOM)

Vol. 2. Issue 2, December 2020

DOI: 10.34097/jeicom-2-Dec2020-4

\section{Li Qing $^{9}$}

Dr Fotini Diamantidaki ${ }^{10}$

\begin{abstract}
Given the impact of coronavirus, all schools across all sectors public and private, in the United Kingdom closed at the end of March 2020. Closures affected every type of establishment across the UK as well as private language schools. Our case study takes place in London and looks into the student experience in a language Mandarin Chinese school. These language students, as very many across the globe, who attended face-to-face sessions up until that point, have since been studying remotely and joining virtual classrooms via Zoom, one of the multiple video conferencing platforms available. To better evaluate students' online learning experience of remote learning, this study examines the teacherstudent interactions that take place via online means and the students' sense of 'presence' (i.e., cognitive, social, and teaching presence) in order to evaluate the lessons we can learn from the online learning experience, going forward in terms of teaching and learning. This study also presents how meaningful and worthwhile the experience has been and how the sense of 'presence' plays a significant role in the process of online teaching and learning.
\end{abstract}

Keywords: online learning experience, interactions, cognitive presence, social presence, teaching presence

\footnotetext{
${ }^{9} \mathrm{PhD}$ candidate, Institute of Education, University College London, UK. E -mail: qing.li.17@ucl.ac.uk

${ }^{10}$ Lecturer in Languages Education, UCL centre of Applied Linguistics, UK. Email: f.diamantidaki@ucl.ac.uk
} 


\section{Introduction}

Given the impact of coronavirus, all schools across all sectors public and private, in the United Kingdom closed at the end of March 2020. Closures affected every type of establishment across the UK as well as private language schools (Scallan et al., 2020; Choi et al., 2020). Our case study takes place in London and looks into the student experience in a language Mandarin Chinese school. These language students, as very many across the globe, who attended face-to-face sessions up until that point, transitioned within a very short amount of time to virtual classes by means of digital resources, in our case Zoom. Although some virtual tools (e.g., Moodle) were previously used for face-to-face lessons, this was the first time that teachers and students transitioned to an entirely online learning set up. To better understand students' online learning experience, especially the impact of nationwide lockdown on L2 Mandarin learning, this study examines teacher-student online interactions and explores students' sense of teaching presence, social presence, and cognitive presence, which contribute to their learning performance and significantly relate to their success and thus further contribute to their feeling of satisfaction (Heckman \& Annabi., 2005; Swan \& Shih, 2005). To investigate the concept of interaction, this study applied the Community of Inquiry model in order to explore the perception of presence in a digital environment and evaluate its significance during the teaching and learning process (Garrison et al., 2000).

\section{Literature Review}

\subsection{Online teaching and learning}

Redmond (2011) suggested four different ways technology in education can be applied according to the parameters of space and time. Firstly, technology is present in the face-toface mode where teaching and learning are in the same geographical location at the same time. Secondly, when learners and teachers interact in the same space but at a time they choose, such as in asynchronous online discussions. Participants working at the same time but located at different geographical places come next, using different media such as video conferencing. And finally, teachers and learners interact amongst different geographical spaces and also different time zones. Redmond's analysis above allows us to gradually situate learning from face to face to blended to entirely online. Blended learning is therefore defined as "the use of two or more distinct methods of training" (Masie, 2002, p.59) such as face to face and online during one course. Allen and Seaman (2003) continued the debate and defined that a blended course is when "having between $30 \%$ and $80 \%$ of the course content delivered online" and going even further as to identifying an online course mainly "at least $80 \%$ of the course content delivered online" (p.6).

During the last few years, online learning has attracted increasing attention from researchers concerning its advantages and disadvantages for teaching and learning (Teng et al., 2011; Florian \& Zimmerman, 2015). Digital technologies have contributed to improving existing teaching approaches and learning outcomes in a way that it has been embedded into the faceto-face mode and worked in blended and online settings (Hativa \& Goodyear, 2001). However, research also shows that teachers' technology use may be limited due to the lack of 
technological skills (Burgan 2006, Chen \& Ko, 2010; Chen et al., 2005; Wang \& Chen, 2008). This might lead to an ambiguous assumption of the role that machines play in the classroom environment. Some teachers may consider machines to be a positive 'presence' in the classroom, allowing connectivity and collaboration, whilst some may view it as a 'machine' that causes lack of interaction amongst participants: "machines for teaching and learning is a question of presence or absence" (Burgan, 2006, p. 100).

Bain (2004) claimed that teaching should not be limited in any way, whether face-to-face or virtual, pointing out that the main challenge was to make any approach fit the purpose of education and keep learning as effective as possible, in order to engage students on a deeper and more meaningful cognitive level. Marshall (2011) discussed that digital teaching should not compromise "the feeling of community, engagement, focused attention and sense of personal responsibility" as valued by teachers and learners in face-to-face settings (Marshall, 2011, p. 19). Bowen (2012), in defence of online learning, suggested that online resources can be benefiting for educational purposes allowing students and teachers to explore various means of collaboration outside the physical classroom, such as using software systems to improve communication or work together within a digital environment. Florian (2010) suggested that online platforms such as Moodle offer both teachers and learners the opportunity to collaborate beyond the physical realms of the classroom, by sharing resources, giving feedback, having synchronous and asynchronous discussions and so on. Hamad (2017) suggested that Blackboard Collaborate provides real-time annotations and interactive whiteboard for virtual teaching allowing students to download lectures and learning materials at any time and thus caters to their learning style (Hamad, 2017).

From the learners' perspective, studies concluded that the majority enjoyed online learning for its efficiency, flexibility, convenience, and self-pacing opportunities (Wang \& Chen, 2007; Wang et al., 2010; Wuensch et al., 2008). For example, by investigating online learning experiences, Wuensch et al. (2008) deduced that students were satisfied in terms of convenience and self-pacing parameters but were less so with regards to communication with classmates and instructors. Similarly, conducting research in an audio-based learning environment, Park and Bonk (2007) reported that students valued timely feedback from instructors and the dynamic nature of the interaction, but highlighted challenges such as online tool problems and time constraints. Heckman and Annabi (2005) pointed out that the dynamics and mutual interactions during the online learning process contribute to students' learning performance.

\subsection{Presence and the Community of Inquiry Model}

Presence is one's subjective sense of existence during the course of interaction with the social or natural environment, involving the individual's perceptive, cognitive, and affective engagement (Draper et al., 1999). Heeter (1992) proposed that "a sense of presence in a virtual world derives from feeling like you exist within but as a separate entity from a virtual world that also exists" (p.2). This virtual experience may be enhanced if the existence is recognized by other beings in this virtual environment or by the environment itself (Heeter, 1992). He further distinguished subjective experiences from three perspectives: the self, other beings, and the surrounding environment, which corresponded to the three dimensions of presence, respectively: personal presence, social presence, and environmental presence. 
Personal presence refers to the individual's subjective feeling of being in the virtual world, which varies from person to person. Social presence relates to the individual's feelings towards other beings' existence and the extent of others' reactions to the individual, such as conversations and activities. Environmental presence is concerned with the interaction between the individual and the setting per se, such as to what extent the settings appear to recognize the individual. This further contributes to the individual's sense of being.

The perception of presence in a digital environment involves the user's feeling of being part of a virtual world and concerns the effectiveness of the digital medium (Ijsselsteijn \& Riva, 2003). Zahorik and Jenison (1998) noted that the degree to which an individual participates being real in a virtual environment is very much determined by the user's own intention and the effective use supported by the digital system in response to the user's action. Daniel (2012) did not regard this sense of being as stable; rather, it is changeable when one moves through the online process over time. Derived from empirical research on students' learning experience in a computer-based environment, Garrison et al. (2000) proposed the Community of Inquiry model (Figure 1) concerning digital education, which is composed of three key elements: cognitive presence, social presence, and teaching presence, with a worthwhile and meaningful educational experience being located within the core.

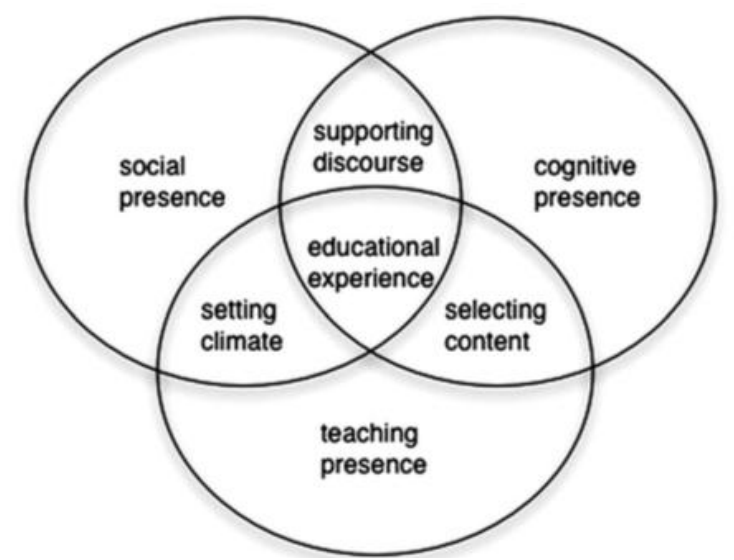

Figure 1. Framework of the Community of Inquiry Model (Garrison et al., 2000)

In this model, cognitive presence refers to the understanding of learning materials, the exploration of the subject, and the resolution concerning the content. This presence involves a reflective and meaning-focused process internal to one's mind, which is essential to learners' worthwhile learning experience to construct their knowledge (Garrison, 2000). Newman et al. (1996 \& 1997) pointed out that online learners may adopt a more serious and worthier style, as a significant difference has been identified between face-to-face and computer-based courses in terms of critical thinking. Specifically, according to their investigation, face-toface learners received more interaction, whereas computer-based learners generated a higher level of critical thinking. Recent studies have also found that students studying online are involved in higher-level cognitive processes compared with those in physical environments (Hastie et al., 2007; Wang \& Chen, 2007). However, cognitive presence alone is not sufficient enough to develop and sustain higher-order thinking skills in an online educational 
environment, especially where collaborative work is much needed. What is also important is the extent of the individual's comfort and participation within the virtual community, which implies social presence (Garrison, 2000).

Social presence refers to how the learners carry themselves, present themselves, project themselves, and interact with others within the online community. The interactions in the community give rise to the individual's sense of being together and the feeling of being connected, as opposed to being isolated (Short et al., 1976; Heeter et al., 2003). In a digital world, communication develops through activities, engagement, management and time spent using the media, all of which help to establish relationships, mutual beliefs and shared knowledge (McInnerney \& Robbert, 2004; Wilhelm et al., 2003). Daniel et al. (2012) postulated that the learners' social presence might be impacted by a sense of belonging to the community, group cohesion, the intensity of members' interactions, etc. It is easier to sustain and enhance cognitive presence in a well-established online community (Garrison, 1997; Gunawardena, 1995).

Teaching presence refers to the learner's perception of the teacher's role as a designer of the course, a guide during learning activities, and an authority in charge of online progress (Hiltz $\&$ Turoff, 2002). The realization of cognitive presence and social presence depends much on the teacher, which is particularly true when it comes to online teaching (Garrison et al, 2000). In fact, the lack of appropriate leadership and direction is a common reason why online teaching or conferences fail (Gunawardena, 1991; Hiltz \& Turoff, 1993). The teacher's behaviour, such as acknowledging student contributions, can affect the efficacy of learning activities to a great extent (Tagg \& Dickenson, 1995). Factors such as course design, facilitation, management, and instruction may also contribute to teaching presence. Generally speaking, learners' social and cognitive presence is very much shaped by teaching presence (Garrison, 2006).

The three types of presence are usually investigated in connection with indicators such as posting and messages. Garrison et al. (2000) categorized these indicators according to these three presences and proposed the coding template shown in Table 1 below: cognitive presence is categorized by triggering event, exploration, integration and resolution. Social presence includes emotional expression, open communication and group cohesion. Teaching presence is composed of course management, building understanding and direct instruction.

To sum up, cognitive presence, social presence, and teaching presence are the main components to understand learners' learning experience in the virtual environment (Garrison, 2006). By applying the Community of Inquiry model, this research examines teacher-student interactions and learners' three dimensions of presence in order to gain insights into learners' experience of online Mandarin learning. Specifically, this research investigates two main questions: 1) What is the nature of the interaction between the teacher and students after the Mandarin course moved online? 2) What are students' three presences like (i.e., cognitive, social and teaching presence) during this online learning experience? 


\begin{tabular}{|c|c|c|}
\hline & & \\
\hline \multirow{2}{*}{$\begin{array}{l}\text { Presences } \\
\text { Cognitive } \\
\text { Presence }\end{array}$} & Categories & Indicators / examples \\
\hline & Triggering Event & $\begin{array}{l}\text { Recognizing the problems/questions, a sense of } \\
\text { puzzlement }\end{array}$ \\
\hline & Exploration & Information exchange, discussion of ambiguities \\
\hline & Integration & Connecting ideas, combining information \\
\hline & Resolution & $\begin{array}{l}\text { Vicariously applying new ideas, critically assessing } \\
\text { solutions }\end{array}$ \\
\hline Social presence & Emotional expression & Emotional interactions, autobiographical narratives \\
\hline & Open communication & Risk-free expression, acknowledging others \\
\hline & Group cohesion & Encouraging collaboration, helping, and supporting \\
\hline Teaching presence & Course management & $\begin{array}{l}\text { Managing content, setting discussion topics, } \\
\text { establishing discussion groups }\end{array}$ \\
\hline & $\begin{array}{l}\text { Building } \\
\text { understanding }\end{array}$ & $\begin{array}{l}\text { Sharing ideas/thoughts, clarifying confusions, } \\
\text { identifying agreement and disagreement }\end{array}$ \\
\hline & Direct instruction & $\begin{array}{l}\text { Focusing and pacing discussion, providing feedback, } \\
\text { pace of presentation }\end{array}$ \\
\hline
\end{tabular}

\section{Methodology}

\subsection{Mandarin course and participants}

This research investigated classes taught by a Mandarin specialist who was teaching three groups at the preliminary, intermediate and higher level. The students comprised a total of 15 adults (4 females and 11 males). One student went back to her home country, Russia, not long after the school closure but continued to participate in the online Mandarin lessons. Therefore, the course was not affected by transferring to a virtual setting in terms of the number of students. Each group had two Mandarin lessons every week and each lesson lasted two hours. The teacher uploaded teaching materials and set homework on the school's Moodle platform. After the lockdown was announced, Zoom was introduced and functioned as a virtual classroom environment. In addition, groups were set up via Skype by the teacher to facilitate communication outside the class times, for the purposes of answering questions and helping students to complete homework assignments.

\subsection{Data}

Two types of data were collected: text messages between students and the teacher, and questionnaires from students. Digital consent forms and information sheets were sent out and then collected from the students from the start, and the participation was voluntary. Participants were free to withdraw during the research without any consequence and then the data would not be used for this purpose. 


\subsubsection{Text messages}

The messages collected in this study were from Skype ${ }^{11}$, where students and the teacher communicated after the lessons over a period of 12 online lessons. For the purposes of this study, the content of messages from the teacher and students were coded into different types, based on the Community of Inquiry model and in reference to other empirical studies (Zhu, 2006; Daniel, 2012). Specifically, the messages between each two lessons were imported into Excel in line with the number of the lessons, and further categorized under the types of messages and the senders (i.e., students and the teacher).

Specifically, there were five types of messages from the teacher in this study:

1. Course facilitation and management.

These were messages concerning the course content or management, for example: "We have finished Chapters 1 and 2; in the next lesson, we will work on Chapter 3"; "Please send your homework to me before the next lesson".

2. Social expression.

This type of expression referred to the teacher's greetings such as "See you all in a minute"; "Hope you all have had a nice day".

\section{Responsiveness.}

These were messages in the form of responses to students' questions, comments or enquiries, such as "That's a very positive and genius plan".

4. Technical issues.

Messages of this type referred to the technical use of online media, such as "Please let me know if you cannot access Moodle"; "I think there is a 'record' button when you join Zoom".

5. Other.

These were other kinds of messages that were not relevant to the course per se.

The content of student-sent messages was coded according to four main types:

1. Cognitive.

Messages consisted of in-depth inquiries and judgemental/explanatory information. The indepth inquiries were about the clarification of the course content, such as "I wanted to ask is this cat with rice? I was confused as it says something different in the English translation". Judgmental/explanatory information were concerned with statements made by students with opinions such as "This video is good too but Bai Yu occasionally speaks quickly".

2. Social.

This was composed by a range of responsive messages (e.g., "Enjoy the rest of the day") when students replied to the teacher and the group to show their participation and appreciation, e.g., "That's so exciting".

\section{Technical.}

These messages were concerned with technical issues, e.g., "I'm having some problems with my internet, just trying to get it to work".

4. Other.

\footnotetext{
${ }^{11}$ As Zoom does not receive messages after the lessons and students usually interact with the teacher verbally during the lesson, there were no text messages taken from Zoom.
} 
These were messages irrelevant to the course, e.g., "My calendar for this month. A positive affirmation calendar".

\subsubsection{Questionnaire}

In order to understand students' subjective sense of social presence, teaching presence, and cognitive presence, a questionnaire (see Appendix) was developed based on the Community of Inquiry model and collected at the end of the 12 lessons. The questionnaire consisted of 30 five-point scale questions ${ }^{12}$ and one open question. Specifically, 26 Likert scale questions addressed students' sense of teaching presence, social presence, and cognitive presence. Four questions were about course content and evaluation, effectiveness, speed, and time management. The open question was designed for any additional comments students wished to express. The questionnaire was piloted in advance by two students from a different Mandarin group. The final questionnaire was collected online anonymously. The data were then imported into and analysed by SPSS 26.0. The consistency reliability coefficients of the variables from this questionnaire were above threshold 0.70 (Bernardi, R. A., 1994).

\section{Results}

\subsection{Messages}

\subsubsection{Overview}

During the 12 lessons, 685 messages were recorded (Table 2): 376 from students (54.9\%), and 309 from the teacher $(45.1 \%)$. On average, students sent about 31 messages and the teacher sent about 26 messages per lesson. Specifically, this equates to almost 4 messages per student per lesson, a high frequency of the interaction between the teacher and students beyond the lessons, considering the population size and the time frame. Moreover, students' messages outnumbered those sent by the teacher in eight out of the 12 lessons. Interestingly, the largest number of student-sent messages was recorded for Lesson $4(n=44)$, while the lowest was recorded for Lesson $3(n=19)$.

Table 2. Summary of Text Messages (L=Lesson)

\begin{tabular}{lcccccccccccccc}
\hline $\begin{array}{l}\text { Msg. } \\
\text { Type }\end{array}$ & L1 & L2 & L3 & L4 & L5 & L6 & L7 & L8 & L9 & L10 & L11 & L12 & Total $\begin{array}{l}\text { Mean } \\
\text { (SD) }\end{array}$ \\
\hline $\begin{array}{l}\text { Student- } \\
\text { sent }\end{array}$ & 34 & 30 & 19 & 44 & 30 & 41 & 42 & 25 & 22 & 32 & 27 & 30 & 376 & $\begin{array}{l}31.33 \\
(7.85)\end{array}$ \\
\hline $\begin{array}{l}\text { Teacher- } \\
\text { sent }\end{array}$ & 21 & 27 & 24 & 25 & 29 & 34 & 28 & 30 & 23 & 17 & 29 & 24 & 309 & $\begin{array}{l}25.91 \\
(4.54)\end{array}$ \\
\hline Total & 55 & 57 & 43 & 69 & 59 & 75 & 68 & 55 & 45 & 49 & 56 & 54 & 685 & $\begin{array}{l}57.08 \\
(9.60)\end{array}$ \\
\hline
\end{tabular}

\footnotetext{
${ }^{12}$ The 5 points are: (1) Strongly disagree; (2) Disagree; (3) Neither agree or disagree; (4) Agree; (5) Strongly agree.
} 


\subsubsection{Student-sent text messages}

The content of the students' messages was further analysed in order to understand their online participation and engagement on the course (Table 3):

Table 3. Content Analysis of Student-sent Messages

\begin{tabular}{|c|c|c|c|c|c|c|c|c|c|c|c|c|c|c|c|}
\hline $\begin{array}{l}\text { Main } \\
\text { Type }\end{array}$ & Sub-type & $\begin{array}{l}\mathrm{L} \\
1\end{array}$ & $\begin{array}{l}\mathrm{L} \\
2\end{array}$ & L3 & $\mathrm{L} 4$ & L5 & L6 & $\begin{array}{l}\mathrm{L} \\
7\end{array}$ & $\begin{array}{l}\mathrm{L} \\
8\end{array}$ & $\begin{array}{l}\mathrm{L} \\
9\end{array}$ & $\begin{array}{l}\mathrm{L} 1 \\
0\end{array}$ & $\begin{array}{l}\mathrm{L} 1 \\
1\end{array}$ & $\begin{array}{l}\mathrm{L} 1 \\
2\end{array}$ & Total & $\begin{array}{l}\text { Mean } \\
\text { (SD) }\end{array}$ \\
\hline \multirow[t]{4}{*}{$\begin{array}{l}\text { Cognitiv } \\
\text { e }\end{array}$} & $\begin{array}{l}\text { In-depth } \\
\text { inquiries }\end{array}$ & 7 & 6 & 4 & 5 & 3 & 8 & 6 & 4 & 6 & 10 & 4 & 9 & $\begin{array}{l}72 \\
(19 \%)\end{array}$ & $6(2.17)$ \\
\hline & $\begin{array}{l}\text { Judgemental/ } \\
\text { explanatory }\end{array}$ & 3 & 2 & 2 & 10 & 4 & 6 & 8 & 5 & 2 & 7 & 6 & 3 & $\begin{array}{l}58 \\
(15 \%)\end{array}$ & $\begin{array}{l}4.83 \\
(2.62)\end{array}$ \\
\hline & Information & & & & & & & & & & & & & & \\
\hline & (Sub-total) & $\begin{array}{l}1 \\
0\end{array}$ & 8 & 6 & 15 & 7 & 14 & 14 & 9 & 8 & 17 & 10 & 12 & $\begin{array}{l}130 \\
(35 \%)\end{array}$ & $\begin{array}{l}10.83 \\
(3.51)\end{array}$ \\
\hline \multirow[t]{3}{*}{ Social } & Affectional & 8 & 1 & 2 & 4 & 2 & 6 & 7 & 3 & 2 & 6 & 3 & 3 & $47(9 \%)$ & $\begin{array}{l}3.91 \\
(2.27)\end{array}$ \\
\hline & Responsive & $\begin{array}{l}1 \\
2\end{array}$ & $\begin{array}{l}2 \\
0\end{array}$ & 11 & 21 & 18 & 19 & 13 & 9 & 10 & 6 & 11 & 14 & $\begin{array}{l}164 \\
(44 \%)\end{array}$ & $\begin{array}{l}13.67 \\
(4.79)\end{array}$ \\
\hline & (Sub-total) & $\begin{array}{l}2 \\
0\end{array}$ & $\begin{array}{l}2 \\
1\end{array}$ & 13 & 25 & 20 & 25 & 20 & 12 & 12 & 12 & 14 & 17 & $\begin{array}{l}211 \\
(56 \%)\end{array}$ & $\begin{array}{l}17.58 \\
(4.93)\end{array}$ \\
\hline $\begin{array}{l}\text { Technic } \\
\text { al }\end{array}$ & & 1 & 0 & 0 & 0 & 0 & 0 & 2 & 0 & 0 & 0 & 0 & 0 & $\begin{array}{l}3 \\
(0.8 \%)\end{array}$ & $\begin{array}{l}0.25 \\
(0.62)\end{array}$ \\
\hline Others & & 3 & 1 & 0 & 4 & 3 & 2 & 6 & 4 & 2 & 3 & 3 & 1 & $32(9 \%)$ & $\begin{array}{l}2.67 \\
(1.61)\end{array}$ \\
\hline Total & & $\begin{array}{l}3 \\
4\end{array}$ & $\begin{array}{l}3 \\
0\end{array}$ & 19 & 44 & 30 & 41 & 42 & 25 & 22 & 32 & 27 & 30 & 376 & $\begin{array}{l}31.33 \\
(7.85)\end{array}$ \\
\hline
\end{tabular}


1. There were 211 out of 376 messages $(56 \%)$ recorded under the social category, which consisted of the social $(n=47) 9 \%$ and responsive types $(n=164) 44 \%$. It was found that most of the social messages were about greetings and farewells. The majority of the responsive messages were responses to the teacher's requests and other students' posts or discussions. The mean of social messages was around four per lesson, while it was around 14 for responsive ones. In fact, the responsive type exceeded not only the affectional type but also all the other types of messages, which confirmed that interaction between the teacher and the students was the most frequent outside the lessons.

2. It was observed that 130 messages sent by students were cognitive type (35\%). Specifically, there were 72 messages about in-depth inquiries made to clarify aspects of the course content (19\%), representing the second largest number among all the messages. There were 58 messages $(15 \%)$ about information posted and shared by students via other online resources (such as YouTube and Twitter), along with expressions of personal judgment or the reasons why they made these recommendations to others. These online resources were relevant to the course but not covered during teaching time.

3. There were only three messages about technical issues during the entirety of the 12 lessons, which suggests that everyone coped well with technology. However, this may have been due to the fact that instructions were sent to them about the use of the technical tools at the beginning, and the IT team from the school was available to help students.

4. There were other messages $(n=32)$ that were recorded but irrelevant to the course, such as discussions about the coronavirus or daily life during the lockdown period. This low figure (9\%) suggests the fact that their communication beyond the lessons on this platform was less about other matters but more about the course.

To summarize, students' messages were more about the responsive interaction (44\%) and indepth thinking (35\%). Messages about technical $(0.8 \%)$ and other issues $(9 \%)$ were the fewest in number. 


\subsubsection{Teacher-sent text messages}

Table 4: Content Analysis of Teacher-sent Messages

\begin{tabular}{|c|c|c|c|c|c|c|c|c|c|c|c|c|c|c|}
\hline Type & L1 & L2 & L3 & L4 & L5 & L6 & L7 & L8 & L9 & L10 & L11 & L12 & Total & $\begin{array}{l}\text { Mean } \\
(\mathrm{SD})\end{array}$ \\
\hline $\begin{array}{l}\text { Course } \\
\text { facilitation \& } \\
\text { management }\end{array}$ & 10 & 18 & 12 & 12 & 7 & 9 & 18 & 12 & 17 & 10 & 13 & 14 & $\begin{array}{l}152 \\
(49 \%)\end{array}$ & $\begin{array}{l}12.67 \\
(3.55)\end{array}$ \\
\hline Responsive & 1 & 3 & 12 & 7 & 10 & 14 & 5 & 13 & 4 & 2 & 9 & 3 & $\begin{array}{l}83 \\
(27 \%)\end{array}$ & $\begin{array}{l}6.92 \\
(4.56)\end{array}$ \\
\hline $\begin{array}{l}\text { Social } \\
\text { expression }\end{array}$ & 2 & 1 & 0 & 2 & 2 & 3 & 2 & 2 & 2 & 3 & 3 & 4 & $26(8 \%)$ & $\begin{array}{l}2.17 \\
(1.03)\end{array}$ \\
\hline $\begin{array}{l}\text { Technical } \\
\text { issues }\end{array}$ & 1 & 0 & 0 & 0 & 0 & 0 & 1 & 0 & 0 & 0 & 0 & 0 & $\begin{array}{l}2 \\
(0.7 \%)\end{array}$ & $\begin{array}{l}0.17 \\
(0.39)\end{array}$ \\
\hline Others & 7 & 3 & 0 & 4 & 10 & 8 & 2 & 3 & 0 & 2 & 4 & 3 & $\begin{array}{l}46 \\
(15 \%)\end{array}$ & $\begin{array}{l}3.83 \\
(3.07)\end{array}$ \\
\hline Total & 21 & 27 & 24 & 25 & 29 & 34 & 28 & 30 & 23 & 17 & 29 & 24 & 309 & $\begin{array}{l}25.91 \\
(4.54)\end{array}$ \\
\hline
\end{tabular}

In Table 4, it can be observed that there were 309 messages sent by the teacher, most of which were about course management and facilitation $(n=152) 49 \%$, with an average of 13 messages sent out per lesson. This could suggest that the teacher deployed the text message as the main tool to manage the course beyond the lessons. It was followed by responsive messages $(n=83) 27 \%$, with seven messages per lesson on average. It is interesting to note that this type varied greatly from lesson to lesson, with only one such message collected from Lesson 1 compared with 14 from Lesson 6. It is identified that that only one from Lesson 1 was about the technical issue raised by a student. The total number of social expressions (8\%) was 26 , while there were only two concerning technical issues $(0.7 \%)$. Other messages $(n=46) 15 \%$ were identified as irrelevant to the course content. To summarize, about half of the messages sent by the teacher were to facilitate or manage the course, with a quarter of the messages being responses to the students. 


\subsection{Questionnaire on learning experience}

Table 5 reveals the overall means from the questionnaire, namely between 4.69 and 4.84 , with cognitive presence receiving the highest $(\mathrm{M}=4.84)$ and overall evaluation the lowest $(\mathrm{M}=4.69)$. As point 5 in this questionnaire means strongly agree, the high ratings given by the students suggest that they strongly agreed that their online learning was a worthwhile and meaningful experience.

Table 5. Students' Perception of Presences

\begin{tabular}{llll}
\hline Presences & Categories & Mean $(\mathrm{SD})$ & Overall mean (SD) \\
$\begin{array}{lll}\text { Teaching } \\
\text { presence }\end{array}$ & $\begin{array}{l}\text { Instructional } \\
\text { management }\end{array}$ & $4.88(0.35)$ & $4.71(0.20)$
\end{tabular}

Building understanding $4.68(0.18)$

Direct instruction $\quad 4.57(0.30)$

Social presence Emotional expression $\quad 4.80(0.31) \quad 4.73(0.53)$

Open communication $\quad 4.72(0.27)$

Group cohesion $\quad 4.69(0.25)$

$\begin{array}{lll}\text { Cognitive } \quad \text { Triggering event } & 4.90(0.20) \quad 4.84(0.60)\end{array}$

presence

$\begin{array}{ll}\text { Exploration } & 4.81(0.41) \\ \text { Integration } & 4.89(0.35) \\ \text { Resolution } & 4.77(0.33)\end{array}$

\begin{tabular}{|c|c|c|}
\hline \multirow[t]{4}{*}{$\begin{array}{l}\text { Overall } \\
\text { evaluation }\end{array}$} & $\begin{array}{l}\text { Online lessons as } \\
\text { whole }\end{array}$ & a $4.68(0.49)$ \\
\hline & Lesson content & $4.70(0.15)$ \\
\hline & Effectiveness & $4.85(0.27)$ \\
\hline & Time management & $4.51(0.76)$ \\
\hline
\end{tabular}


1. Within the cognitive presence category, triggering events $(\mathrm{M}=4.90)$ and integration $(M=4.89)$ were rated the highest among all the variables, which suggests that students strongly concurred that the triggering events posted by the teacher were thought-provoking and they engaged in the course cognitively to a great extent (e.g., connecting ideas and combining information). The score for exploration $(M=4.81)$ and resolution $(M=4.77)$ were also high, which means that the course substantially assisted the students to explore information sources and resolve content-related questions.

2. The scores for social presence and teaching presence were similar at 4.73 and 4.71 , respectively. In terms of social presence, emotional expression $(M=4.80)$ indicates that most of the students agreed that the course gave them a sense of belonging for social interaction. Open communication ( $\mathrm{M}=4.72)$ could mean that the majority felt comfortable participating in the course discussion and were open to expressing their thoughts. Group cohesion $(\mathrm{M}=4.69)$ suggests that this course helped them to develop a sense of collaboration within their groups. Overall, the score for social presence could be interpreted that students had a good sense of belonging and enjoyed the social interaction with other participants.

3. As to teaching presence, instructional management was rated the highest $(M=4.88)$, followed by building understanding $(\mathrm{M}=4.68)$. This could indicate that the majority of the students were satisfied with the teacher's course management and agreed that the teacher played a positive role in guiding the students' understanding of the course. The relatively low score for direct instruction ( $M=4.57)$ might be explained, to some extent, by the fact that the teacher's instruction, such as her presentation and timely feedback, was not as clear or direct as expected.

4. In terms of an overall evaluation, the online Mandarin lessons were given a value of 4.69 by the students. Specifically, most of the students were pleased with the course as a whole $(\mathrm{M}=4.68)$, as well as its content $(\mathrm{M}=4.70)$. The course was regarded as effective by the majority $(\mathrm{M}=4.85)$. The relatively low time management $(\mathrm{M}=4.51)$ may be due to the fact that, during the online lessons, the teacher was unable to adjust the teaching pace as quickly as was the case in the face-to-face classes. 
Regarding the open question where comments or feedback were required, most of them were positive $^{13}$ to online learning in terms of its communication and technical usage. Online tools, such as white board, helped them to back up information efficiently.

"I like how we still can communicate like we are in the classroom".

"I can see clearly on my laptop a post to the white board and I can back to all information we are writing in board".

One aspect concerned the feedback given was even better provided online in this study:

"There aren't any problems of taking online courses and even sometimes it's better in some occasions such as receiving more direct detailed feedback".

However, one student raised some issues concerning internet connectivity and Mandarin handwriting in comparison with face-to-face lessons as follows:

"Everything about the course and the online course has been great. The only issues would be that sometimes there are connectivity issues and things can take longer to load as opposed to in a face-to-face course and that it is more difficult sometimes to practice our writing and have this checked or tested by the teacher on the online platform".

This comment suggests that, although there were only three technical issues recorded from the text messages, there would always be a question as to how convenient the technology is for online lessons, as compared with face-to-face lessons, when teachers can give out handouts more easily. This feedback also draws attention to the difficulty of writing practice in online Mandarin learning. In this study, the character writing may be a unique challenge as stroke orders are relatively complicated, especially for students from the background of Latin-based languages. However, this taps into a more generic issue on the specifics of subject pedagogy generated by online teaching.

\section{Discussion and Recommendations}

\subsection{Discussion on messages}

In this study, the number of messages $(\mathrm{N}=685)$ indicates a high frequency of interaction beyond the lesson time. The student-sent messages were more responsive (44\%), which may point to a good sense of community established among the students, as interactions in a community contribute to individual's sense of togetherness (Short et al, 1976; Heeter et al., 2003; McInnerney \& Robbert, 2004; Wilhelm et al., 2003). The cognitive messages (35\%) were recorded as the second highest type sent by student, which indicates that the messaging assisted the students' study beyond the lesson time and facilitated their progress to some extent. This responds positively to Bain (2012)'s call for adopting any approach to assist

\footnotetext{
${ }^{13}$ the comments reproduced are as written
} 
students' effective learning for the purpose of education. The participants' messages also confirmed that they used digital media mainly for the course-specific reasons as the other messages (9\%) irrelevant to the course were the fewest in the record. The content of the messages concerning online resources shared with students $(15 \%)$ suggests that the online resources provided a unique opportunity for teaching and learning, as pointed out by Bowen (2012).

Compared with the students, the teacher-sent messages account for $45.1 \% \quad(n=309)$ in comparison with 54.9\% ( $\mathrm{n}=54.9)$, which may negate some doubts on the faculty use of technology (Burgan, 2006; Chen \& Ko, 2010; Chen et al., 2005; Wang \& Chen, 2008). It also shown that the teacher used messages mainly for course facilitation and management (49\%), which may contribute to the course as a whole. Both the teacher and the students experienced only a few technical issues from the messages data. However, these issues may have been resolved by the IT helpdesk set up online by the school. Therefore, further data concerning this issue are suggested to be collected from the IT team and addressed for future research.

\subsection{Discussion on questionnaires}

The data collected from the questionnaires gave a holistic impression of the online lessons, with all scores above 4.50. It indicates that students strongly agreed that they enjoyed the online learning to a great extent. The learners' positive attitude towards online learning is in accordance with other findings (Wang and Chen, 2007; Wang et al., 2010; Wuensch et al., 2008). Specifically, the score for cognitive presence $(M=4.84)$ was in line with previous findings that online learners are involved in a high level of critical thinking (Newman et al., 1997; Wang \& Chen, 2007). However, in this study, this could also be explained by the fact that all of the students were adults who were capable of grasping information related to their knowledge levels and were more responsible regarding their own study self-discipline. The score for social presence $(M=4.73)$ could suggest that the students established a close community online, which further helped them to sustain and enhance cognitive presence (Garrison, 1997; Gunawardena, 1995). The teaching presence $(M=4.71)$ could have contributed to students' cognitive and social presence in this study, as suggested by Garrison (2000, 2006). Moreover, the comments and feedback from the open question confirmed again that most of the students were positive about online teaching, such as its convenience and direct detailed feedback (Wang et al., 2010; Park \& Bonk, 2007; Wang \& Chen, 2007), which is in accordance with the high rating scores from the questionnaire as well as the highly frequent interaction via messaging.

The downsides of online learning were also brought up in comparison with physical teaching such as the lack of face-to-face supervision. The same issues have been previously addressed by Park and Bonk (2007). The character writing concern raised by the student also increases the attention to the subject-specific difficulties which may occur in online teaching. This character check issue might be particular to Mandarin learning, but it reveals a general concern with inefficient aspects of online education. As Redmond (2011) pointed out, what worked for the face-to-face classroom may be not as effective in the online space to some extent. The challenge is to systematically explore and reinforce the integration of pedagogical practices and technological tools, which will advance digital education in the future 
(Redmond, 2011; Garrison et al., 2010). In essence, we need to be optimistic as online learning and teaching entails a high level of students' satisfaction and interest (Ali, 2020). The technology has become a potent driving force in transforming the educational landscape across the world especially during these unprecedented circumstances that we all live in (Ali, 2020, 2019).

\subsection{Recommendations}

Given that this was a small-scale research project and messages were only collected from 12 Mandarin lessons, there are more questions concerning online education that need to be explored and answered in the future according to the following parameters: More students could be involved to validate the findings in terms of student numbers and age; More language courses could be investigated and compared to derive a comprehensive picture of online language education; It would be beneficial to compare the difference between online and face-to-face lessons in terms of effectiveness. It would also worth considering individual student's actual environment while attending online lessons, such as the disruption from their background or family interference, as this immediate environment may affect their engagement to some extent; Finally, it would be interesting to determine whether there are any differences when comparing lockdown and normal circumstances, considering that all students and teachers had to migrate to online classes in the lockdown period while the same does not apply for the latter.

\section{Conclusion}

Conducted during Covid-19, this study provides an insight of online Mandarin teaching and learning that contributes to pedagogical applications for future digital education. By analysing the primary materials (i.e., text messages) and administering questionnaires, this research found that this online Mandarin course was highly valued by students, especially after they had already received face-to-face lessons. The messages data has shown that digital media provided useful platforms for students to communicate and share resources and for the teacher to help them beyond the lessons. These interactions on this digital platform were more for the purpose of learning and less for other irrelevant matters. This further impacted on the students' sense of belonging in a positive way and facilitated the learning progress. The questionnaire data confirmed that the students' sense of cognitive, social and teaching presence was high online, and emphasized that online teaching and learning is valuable. However, we should bear in mind that, students' social presence and the teachers' teaching presence are integrated components contributing to the overall learning experience. Without high-level teaching and social presence, cognitive presence alone may not be valuable enough for a worthwhile and meaningful online education. Therefore, it is recommended to integrate the three presences in teaching to provide learners with a valuable digital education experience. Although there are particular disadvantages, such as the supervision of writing characters for this particular study, the issues concerning online teaching and learning need to be investigated and addressed by researchers and teachers from 
Vol. 2, Issue 2 (December 2020), JEICOM

all teaching fields. In doing so, digital education will bring more benefits within a new and changing education landscape. 


\section{References:}

Ali, W. (2019). The Efficacy of Evolving Technology in Conceptualizing Pedagogy and Practice in Higher Education. Journal of Higher Education Studies, 9(2), 81-95.

Ali, W. (2020). Online and Remote Learning in Higher Education Institutes: A Necessity in light of COVID-19 Pandemic. Higher Education Studies, 10(3), 16.

Allen, I. E., \& Seaman, J. (2003). Sizing the opportunity: The quality and extent of online education in the United States, 2002 and 2003. Retrieved from http://www.sloamc.org/resources/sizing_opportunity.pdf

Bain, K. (2004). What the best college teachers do. Cambridge, MA: Harvard University Press.

Burgan, M. (2006). What ever happened to the faculty? drift and decision in higher education. Baltimore, Md: Johns Hopkins University Press.

Bernardi, R. A. (1994). Validating research when Cronbach's alpha is below 0.70: A methodological procedure. Educational and Psychological Measurement, Vol. 54, 766775 .

Chen, N. S., \& Ko, L. (2010). An online synchronous test for professional interpreters. Educational Technology and Society, 13(2), 153-165.

Chen, N. S., Ko, H. C., Kinshuk, \& Lin, T. (2005). A model for synchronous learning using the Internet. Innovations in Education and Teaching International, 42(2), 181-194.

Chen, N. S., \& Wang, Y. (2008). Testing principles of language learning in a cyber face-toface environment. Educational Technology and Society, 11(3), 97-113.

Chen, Y. H., Chen, N. S., \& Tsai, C. C. (2009). The use of online synchronous discussion for web-based professional development for teachers. Computers \& Education, 53(4), $1155-1166$.

Choi, Byung, Jegatheeswaran, Lavandan, Minocha, Amal, Alhilani, Michel, Nakhoul, Maria, \& Mutengesa, Ernest. (2020). The impact of the COVID-19 pandemic on final year medical students in the United Kingdom: A national survey. BMC Medical Education, 20(1), 1-11.

Draper, J. V., Kaber, D. B., \& Usher, J. M. (1999). Speculations on the value of telepresence. CyberPsychology and Behavior, 2(4), 349-362.

Florian, T. (2010). Confidence-based assessment in Moodle: Insights from teachers, administrators, and programmers. ProQuest Dissertations and Theses.

Gunawardena, C. N. (1995). Social presence theory and implications for interaction and collaborative learning in computer conferences. Paper presentation at The 4th International Conference on Computer Assisted Instruction (Hsinchu, Taiwan). 
Gunawardena, C. N. (1991). Collaborative learning and group dynamics in computermediated communication networks. In Research monograph of the American center for the study of distance education (Vol. 9, pp. 14 -24). University Park, PA: The Pennsylvania State University.

Garrison, D. R. (1997). Computer conferencing: The post-industrial age of distance education. Open Learning DIP.

Garrison, D. R. (2006). Online collaboration principles. Journal of Asynchronous Learning Networks, 10(1). http://www.sloan-c.org/publications/jaln/v10n1/pdf/

Garrison, D. R., Anderson, T., \& Archer, W. (2000). Critical inquiry in a text-based environment: computer conferencing in higher education. The Internet and Higher Education, 2(2-3), 87-105.

Hamad, M. M. (2017). Pros \& Cons of Using Blackboard Collaborate for Blended Learning on Students Learning Outcomes. Higher Education Studies,7(2), 7.

Hastie, M., Chen, N. S., \& Kuo, Y.-H. (2007). Instructional design for best practice in the synchronous cyber classroom. Educational Technology and Society, 10(4), 281-294.

Hativa, N., \& Goodyear, P. (2001). Teacher thinking, beliefs and knowledge in higher education. Dordrecht: Kluwer.

Heckman, R., \& Annabi, H. (2005). A content analytic comparison of learning processes in online and face-to-face case study in discussions. Journal of Computer-mediated Communication, 10(2). http://jcmc.indiana.edu/vol10/issue2/heckman.html.

Heeter, C. (1992). Being there: the subjective experience of presence. Presence: Teleoperators and Virtual Environments, 1(2), 262-271.

Heeter, C., Gregg, J., Climo, J., Biocca, F., \& Dekker, D. (2003). Telewindows: case studies in asymmetrical social presence. In G. Riva, \& W. A. IJsselsteijn (Eds.), Being there: concepts, effects and measurement of user presence in synthetic environments (pp. 279293). Amsterdam, The Netherlands: IOS Press.

Hiltz, S. R., \& Turoff, M. (1993). The network nation: Human communication via computer. Cambridge, MA: MIT Press.

Hiltz, S. R., \& Turoff, M. (2002). What makes learning networks effective? Communications of the ACM, 45(4), 56-59.

Ijsselsteijn, W. A., \& Riva, G. (2003). Being there: the experience of presence in mediated environments. In G. Riva, F. Davide, \& W. A. IJsselsteijn (Eds.), Being there: Concepts, effects and measurements of user presence in synthetic environments (pp. 316). Amsterdam, The Netherlands: IOS Press.

Leo, T., Manganello, F., Pennacchietti, M., Pistoia, A., Kinshuk, \& Chen, N. S. (2009). Online synchronous instruction: Challenges and solutions. Paper presented at the 9th 
IEEE International Conference on Advanced Learning Technologies (ICALT 2009), Riga, Latvia.

Masie, E. (2002). Blended learning: The magic is in the mix The ASTD e-learning handbook (pp. 58-63). New York: McGraw-Hill.

Marshall, S. (2001). More face to face, less face to screen. The Chronicle of Higher Education. http://chronicle.com.

McInnerney, J. M., \& Roberts, T. S. (2004). Online learning: social interaction and the creation of a sense of community. Educational Technology \& Society, 7(3), 73-81.

Newman, D. R., Johnson, C., Cochrane, C., \& Webb, B. (1996). An experiment in group learning technology: Evaluating critical thinking in face-to-face and computersupported seminars. Interpersonal Computing and Technology: An Electronic Journal for the 21st Century, 3(2), 56-72.

Newman, D. R., Webb, B., \& Cochrane, C. (1997). Evaluating the quality of learning in computer supported co- operative learning. Journal of the American Society for Information Science, 2(3), 78-92

Park, Y. J., \& Bonk, C. J. (2007). Synchronous learning experiences: distance and residential learners' perspectives in a blended graduate course. Journal of Interactive Online Learning, 6(3), 245-264.

Redmond, P. (2011). From face-to-face teaching to online teaching: Pedagogical transitions. In G. Williams, P. Statham, N. Brown \& B. Cleland (Eds.), Changing Demands, Changing Directions. Proceedings ascilite Hobart 2011. (pp.1050-1060).

Short, J., Williams, E., \& Christie, B. (1976). The social psychology of telecommunication. London: Wiley.

Scallan, Samantha, \& Lyon-Maris, Johnny. (2020). The educational impact of COVID-19: Views from UK GP educators and trainees. Education for Primary Care, 1-2.

Swan, K., \& Shih, L. F. (2005). On the nature and development of social presence in online course discussions. Journal of Asynchronous Learning Networks, 9(3), 115-136.

Timothy P Florian, \& Jay P Zimmerman MA. (2015). Understanding by Design, Moodle, and Blended Learning: A Secondary School Case Study. Journal of Online Learning and Teaching, 11(1), 120.

Tagg, A. C., \& Dickenson, J. A. (1995). Tutor messaging and its effectiveness in encouraging student participation on computer conferences. Journal of Distance Education, 3(2), $121-140$

Wang, Y., \& Chen, N. S. (2007). Online synchronous language learning: SLMS over the Internet. Innovate: Journal of Online Education, 3(3), 56-78 
Wang, Y., Chen, N. S., \& Levy, M. (2010). Teacher training in a synchronous cyber face-toface classroom: characterizing and supporting the online teachers' learning process. Computer Assisted Language Learning, 23(4), 277-293.

Wilhelm, S., Rodehorst, K., Young, S., Jensen, L., \& Stepans, M. B. (2003). Students' perspective of the effectiveness of an asynchronous online seminar. Journal of Professional Nursing, 19(5), 313-319.

Wuensch, K. L., Aziz, S., Ozan, E., Kishore, M., \& Tabrizi, M. H. N. (2008). Pedagogical characteristics of online and face-to-face classes. International Journal on E-learning, $7(3), 523-532$.

Zahorik, P., \& Jenison, R. L. (1998). Presence as being-in-the-world. Presence: Teleoperators, and Virtual Environments, 7(1), 78-89. 


\section{Appendix:}

We would like to invite you to answer the following questions about your experience of online Mandarin learning. This questionnaire is not a test so there are no "right" or "wrong" answers and you do not even have to write your name on it. We are interested in your personal opinion. The results of this survey will be used only for research purposes so please give your answers sincerely, as only this will ensure the success of this survey. If you decide in the end that you would prefer not to participate in this survey, you will be free to opt out without any consequence.

Thank you very much for your help!

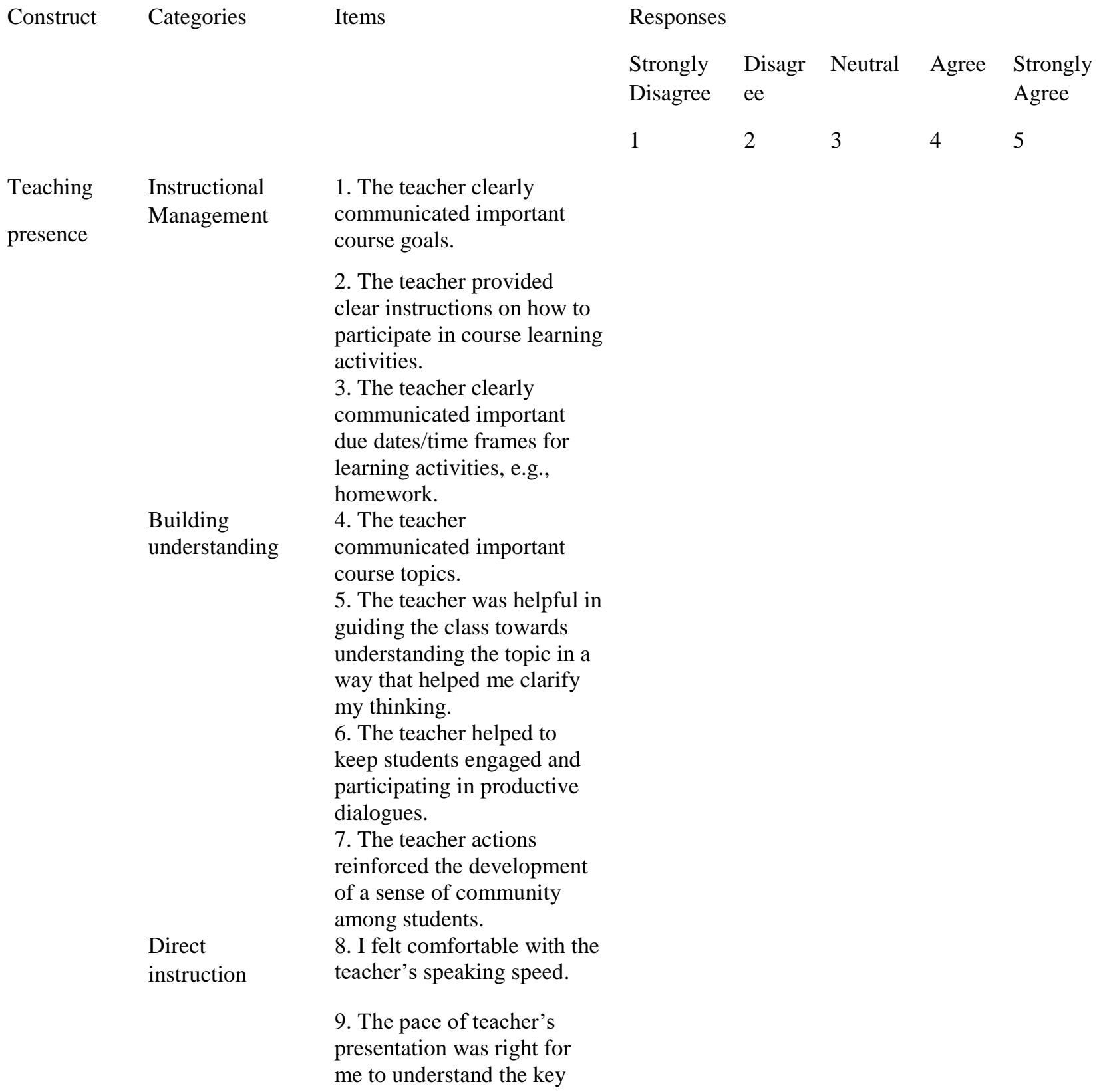


points of the lesson.

10. The teacher provided feedback in a timely fashion.

\section{Social Emotional}

presence expression

Open

communication

Group cohesion

Cognitive presence
11. Getting to know other students gave me a sense of belonging in the course. 12. I was able to form distinct impressions of some students.

13. Online Classroom provided adequate tools for social interaction.

14. I felt comfortable conversing through the tools provided by online teaching and learning.

15. I felt comfortable interacting with other students online.

16. I felt comfortable disagreeing with other students while still maintaining a sense of trust. 17. I felt that my point of view was acknowledged by other students.

18. Online discussions with other students help me to develop a sense of collaboration.

Triggering event

19. Problems/Questions raised by other students increased my interest in course issues.

20. I felt motivated to explore content-related questions.

Exploration 21. I utilized a variety of information sources to explore problems/questions raised in this course.

22. Brainstorming and finding relevant information helped me resolve contentrelated questions.

23. Online discussions were valuable in helping me appreciate different perspectives.

Integration 24. I was able to combine information learned from different resources to answer questions raised in course activities.

25. I was able to reflect on course content and discussions to understand fundamental concepts in this 
class.

26. I can describe ways to
apply the knowledge created
in this course in some e-
learning practices or other
non-class related activities.

$\begin{array}{lllll}\begin{array}{l}\text { Very } \\ \text { Poor }\end{array} & \text { Poor } & \text { Neutral } & \text { Good } & \begin{array}{l}\text { Very } \\ \text { Good }\end{array} \\ 1 & 2 & 3 & 4 & 5\end{array}$

Overall

impression

27. This online course as a whole was

28. The course content was

29. The effectiveness of this online course format was

30. The distribution of time among presentation, Q \& A, and time to lighten the cognitive load (using music, video) was

Is there anything else you would like to say about your online Mandarin learning?

By submitting this questionnaire, I agree that my answers, which I have given voluntarily, can be used anonymously for research purposes.

Thank you again for your cooperation! 


\section{Book review \\ "Why is it worth waking up every morning? \\ Impressions and reflections on inspiration, motivation, and collaboration"}

Dr Sotirios Maipas ${ }^{14}$
Journal of Education, Innovation and Communication (JEICOM)

Vol. 2. Issue 2, December 2020 DOI: 10.34097/jeicom-2-Dec2020-5

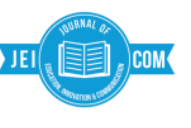

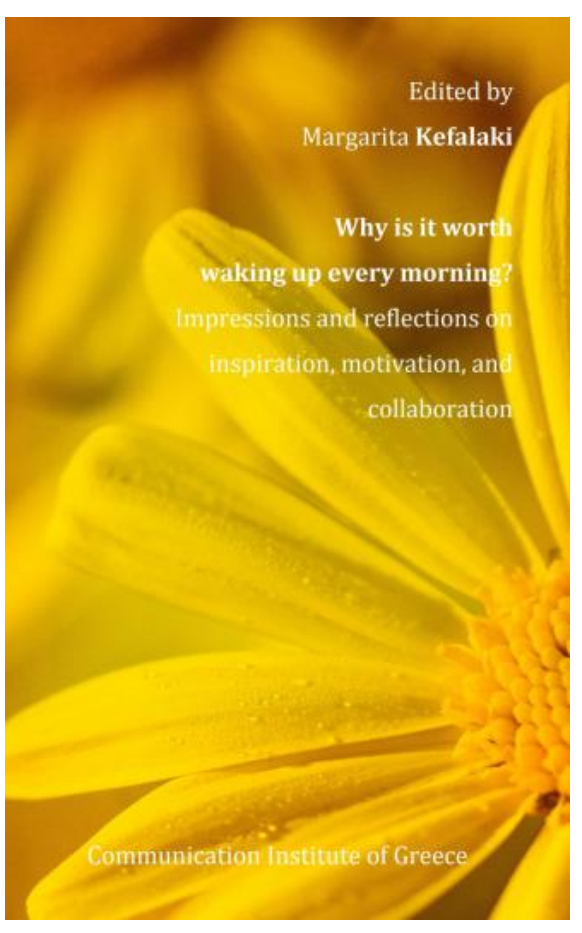

This is a review of the book: "Why is it worth waking up every morning? Impressions and reflections on inspiration, motivation, and collaboration", 2020, edited by Margarita Kefalaki, Communication Institute of Greece.

Why is it worth waking up every morning? One simple question, a million different answers. An eye-catching question over a yellow flower that invites readers to a lifelong adventure of love, hope and fight for a better common future.

This new book edited by the president of the Communication Institute of Greece, Dr. Margarita Kefalaki, is a product of an inspirational collaboration mainly between the president and the honorary vicepresidents of the Institution. A group of ten contributors from different countries have collaborated to prepare this little book which is full of positivity, love and hope.

\footnotetext{
${ }^{14}$ Writer, Physicist MSc, PhD, MBA Cd, Research Associate at Master Program "Environment and Health. Management of Environmental Health Effects", School of Medicine, National and Kapodistrian University of Athens, Greece. E-mail: sotgmaip@gmail.com
} 
Although the main language of the book is the English language, its motivational phrases are translated into eight different official languages (Chinese, Danish, English, French, German, Italian, Portuguese, and Russian), and one German dialect (Trierer Platt). However, one demanding reader would reasonably expect one more language, which is widely spoken, i.e. Spanish. The editor and the contributors may consider adding more languages in a newer version of this worth-reading piece of literature!

The question "Why is it worth waking up every morning?" is being answered 7 times. I do not know if the number " 7 " was selected on the basis that a week has 7 days. However, I do know that these 7 answers were enough to make me remember that the simple things are the most important ones, and how these simple things overcome every "physical" or imaginary border between humans.

Miracles that surround us, such as the sun and the sea, and the invisible glues between us, such as the love and the need for communication are evident in the answers given. Moreover, the faith in our ability to create a worth-living global community is also evident and inspiring.

Indeed, 2020 was one of the most challenging years of recent history. The importance of these miracles and "glues" empower us with the strength to fight, to keep dreaming, and to protect our loved ones. Obviously, this book is a chance to see how we can make the world a better place to live through the belief in neglected values, cooperation, open-mindedness, constant effort, mutual understanding, and communication which has evolved to a real challenge during 2020.

I would describe this book as an intercultural, inspirational little break from our everyday thoughts. All the contributors to the book are scientists and experienced writers. Their scientific way of thinking becomes more than obvious when they accompany their texts with very interesting references to support their arguments. The meaning of their words, and the truth behind them are inspirational to all of us. Also, the carefully selected images and poems travel us to another dimension, where the answer to the question in the book title is the main purpose of our life.

Another impressive facet of the book is how its everyday simplicity, despite the absence of eye-catching graphics and professional photos, directly speaks to the readers' hearts. The book left me with a really large number of positive thoughts. It reminded me that caring about each other is a contagious medicine, necessary to fight the ongoing health crisis and other crises, yet unknown to us. Is this little book a must-read? Surely, it is a must-felt.

This journal provides immediate open access to its content on the principle that making research freely available to the public supports a greater global exchange of knowledge. You can Share - Copy and redistribute the material in any medium or format for any purpose, even commercially, under the terms of the Creative Commons Attribution License (CC BY). The use, distribution or reproduction is permitted, provided the original author(s) and the copyright owner(s) are credited and that the original publication in this journal is cited, in accordance with accepted academic practice. No use, distribution or reproduction is permitted which does not comply with these terms. 